\title{
Characterization of flavonoids from candidate striga grass in controlling diet legumes Cicer arietinum and Vigna radiata
}

\author{
ANYANGO ANNA AKUMU ${ }^{1}$, HUDSON NYAMBAKA ${ }^{2, \vartheta}$, SERGE PHILIBERT KUATE $^{3}$, BALDWYN TORTO ${ }^{3}$ \\ ${ }^{1}$ School of Pure and Applied Sciences of Kenyatta University. Nairobi, Kenya \\ ${ }^{2}$ Department of Chemistry, Kenyatta University. Nairobi, Kenya.`email:hudsonyambaka@yahoo.co.uk \\ ${ }^{3}$ Department of Behavioural and Chemical Ecology, International Center of Insect Physiology and Ecology. Nairobi, Kenya
}

Manuscript received: 24 March 2018. Revision accepted: 26 August 2018.

\begin{abstract}
Akuтu AA, Nyambaka H, Kuate SP, Torto B.2018. Characterization of flavonoids from candidate striga grass in controlling diet legumes Cicer arietinum and Vigna radiata. Biofarmasi J Nat Prod Biochem 16: 83-98. In Africa, intercropping of some legumes with cereal plants has been noticed to generate a remarkable reduction of Striga invasion and enhanced cereal crop production. Desmodium uncinatum administers Striga invasion in intercrop with cereals through an allelopathic technique, including post-sprouting accretion inhibitors emanating from the roots. Having the potential to be a new technique for grass administering, Allelopathy is a natural and environmentally friendly method. A standardized profiling technique based on Reverse Phase-High Performance Liquid Chromatography (RP-HPLC) and Liquid Chromatography coupled with Mass Spectrometry (LC/MS) was utilized to determine flavonoids in extracts of chickpea (Cicer arietinum) and mung bean (Vigna radiata), potential trap plants for Striga grass. Nine flavonoids involving mono-and diglycosyl derivatives of fisetin, baicalein, rhamnetin, isorhamnetin, formononetin, quercetin, isosakuranetin, and sakuranetin were temporarily distinguished. The obtained phenolics were available at concentrations higher than $0.001 \%$ of the dry materials. Many of these phenolic mixtures have been claimed to possess human health advantages. These glycosylated flavones are noted for the first time in these two species. The comprehensive analysis of the polar secondary metabolites in these leguminous plants was useful for comprehending their inhibitory chemistry and proposed biosynthesis by C-glucoside characteristics. All the segregated and described mixtures in the diet legume $C$. arietinum were O-glucosylated. At the same time, Food legume V. radiata should be observed further to see if it can attain Desmodium's allelopathic ability since it possesses inhibitory chemistry and proposed biosynthesis by $\mathrm{C}$-glucosylation.
\end{abstract}

Keywords: Cicer arietinum, control, flavonoids, legumes, Striga, Vigna radiata

\section{INTRODUCTION}

Striga is one of the most significant pests that affect food production in the tropics (Esilaba 2006). The grass problem is aggravated by its reproductive capability; a single plant can deliver over 50,000 grains, which can still be practicable in the soil for 15-20 years (Kureh et al. 2003). The parasite is a serious pest that primarily impends maize production in Kenya, resulting in harvest losses of between 65 to100\%. Degradation in soil fertility is one of the principal reasons for the increment in Striga incidence (Esilaba 2006). Striga hermonthica (Del.) Benth is most common on heavy soil, particularly in the densely populated parts of the Lake Victoria region of western Kenya; simultaneously, $S$. asiatica is noticed in the coast province and seriously damages upland rice (Esilaba 2006).

Research efforts have distinguished several administering options that effectively reduce Striga damage and emergence. These include host plant resistance, utilization of trap plants, and the improvement and maintenance of soil fertility through cereal-legume rotation/intercropping or application of organic or inorganic nitrogen (Kureh et al. 2003). However, because of ecological concerns, environmental health problems, and an increment in herbicide-resistant grass resulting from synthetic herbicides, considerable efforts in designing grass administering strategies of utilizing allelopathic mixtures as bioherbicides is considerable subdue grass is receiving examination (Zaji 2011).

Trap plants are non-host plants that induce Striga grains sprouting but are not parasitized by the grass (Kureh et al., 2003). They could generate suicidal grass sprouting, which decreases the soil's grain bank or attachment to the host when intercropped in maize (Othira et al. 2008). Some legume diversities, for example, chickpea, mung beans, cowpea (Vigna unguiculata L.), groundnut (Arachis hypogaea L.), and soybeans (Glycine max Merrr.), possess the potential to generate suicidal sprouting of $S$. hermonthica, decrease attachment to host and increase the fertility of the soil (Kureh et al. 2003) by adding to the soil with nitrogen and organic matter.

The life cycle of Striga ssp. consists of five stages; sprouting, haustorium initiation, penetration of host tissue, physiological compatibility, and parasite accretion and maturation. Apart from normal grain sprouting requisites, the grass needs a chemical stimulation for sprouting and a second chemical signal to trigger haustorium formation, connecting Striga roots to its host for fount procuration (Othira et al. 2008). However, trap plants release chemicals that induce Striga ssp. Grain sprouting does not produce haustorium signals, nor are they attacked by the parasite (Othira et al. 2008). 

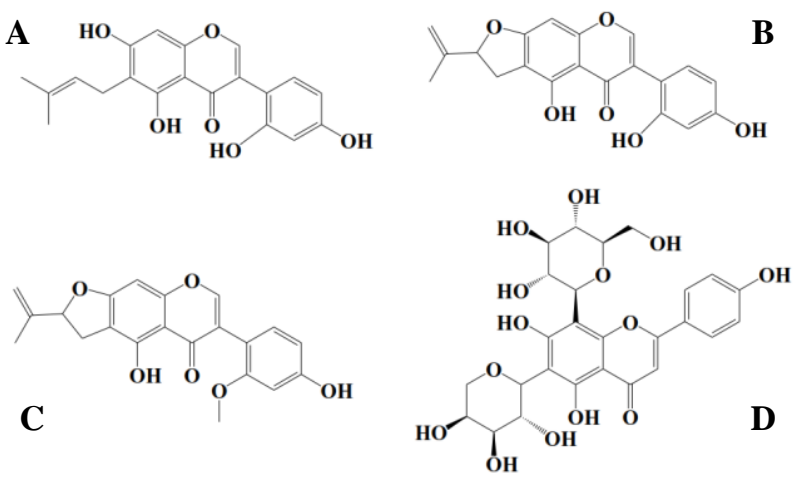

Figure 1. Segregated mixtures from $D$. uncinatum I.5,7, 2',4'tetrahydroxy-6-(3-methylbut-2-enyl) isoflavanone (A), 4", 5"dihydro-5, 2',4'-trihydroxy-5"-isopropenylfurano-(2",3",7,6)isoflavone (B), 4",5"-dihydro-2"-methoxy-5,4'-dihydroxy-5"isopropenylfurano-(2",3",7,6)-isoflavone $(\mathbf{C})$ and isochaftoside (D)

Even though the witch-grass, Striga ssp., is competent for photosynthesis once it grows, it depends on the host plant for an important portion of its carbon provision. Beyond the encumbrance of dispossessing diet and water to these parasites, host plants undergo a characteristic malady resembling severe drought symptoms, involving leaf scorching and increased root: shoot ratios as if a hex had befallen the crop the result of hormonal perturbation or toxic produced by the parasite. Invasion is generally much less severe, where water and soil fertility are optimal for crop accretion (Rich and Ejeta 2008).

Some understanding has been gained of the secondary metabolism included in the technique by which desmodium subdues Striga (Tsanuo et al. 2003). Phytochemical studies of various plants of Desmodium species have progressively segregated phenolic components (Tsai et al., 2011). From Desmodium uncinatum root, 2"'-O-glucosylvitexin, vitexin, isovitexin, and apigenin have been segregated (Tsanuo et al. 2003; Guchu 2007).

Tsanuo et al. (2003) and Hooper et al. (2010) segregated three isoflavanones, 5, 7, 2',4'-tetrahydroxy-6(3-methylbut-2-enyl)-isoflavanone, (A) 4",5"-dihydro5,2',4'-trihydroxy-5"'-isopropenyl furano-(2",3", 7,6)isoflavanone (B) and 4", 5"'-dihydro-2'-methoxy-5,4'dihydroxy-5"-isopropenylferano-(2",3",7,6)-isoflavone (C) from the root exudates of $D$. uncinatum. Segregated fractions comprising mixture B induced sprouting of Striga grains, while fractions comprising mixture $\mathrm{C}$ impeded radical accretion. Pickett et al. (2007) and Hooper et al. (2009) described another key haustorium accretion impeder, di-C-glycosylflavone-6-C- $\alpha$-L-arabinopyranosyl8 -C- $\beta$-D-glucopyranosylapigenin, which is also known as isoschaftoside (D) from a polar fraction of D. unicinatum root exudates (Khan et al. 2010) (Figure 1).

The active components in desmodium root exudates described are suspected of having existed in traditional diet legumes. If resemblant characteristics were noticed in the diet legumes, then conventional breeding could be utilized to pick out and increase the characteristics. On the other hand, if these characteristics were lacking, a gene could be transferred directly from Desmodium into diet legumes via a genetic modification to allow legumes to subdue Striga spp. In the long term, it is likely to transfer the same characteristic to cereal plants through heterologous gene expression, especially to the open-pollinated diversities, rather than hybrids for more convenient availability to little scale farmers (Pickett et al. 2010).

The goals of this research were (i) to fractionate and segregate the secondary metabolites from leaf and root tissues of $C$. arietinum and the root of $V$. radiata extracts, utilizing column chromatography, TLC, and RP-HPLC; (ii) to describe the segregated mixtures from $C$. arietinum and $V$. radiata utilizing RP-HPLC and LC-MS.

\section{MATERIALS AND METHODS}

\section{Study design}

This was an experimental design in which chemical mixtures in aqueous extracts of leaves and roots of the legumes $C$. arietinum and $V$. radiata were segregated utilizing column chromatography and RP-HPLC and then described utilizing the RP-HPLC and LC-MS.

\section{Samples and sampling procedure}

Certified grains of Cicer arietinum L. (Desi (SCP 2), Kabuli (SCP 1) types), and Vigna radiata L. (KS 20) was gained from Simlaw Seeds Co., Nairobi, Kenya. The grains were cultivated in July 2011 at the Duduville campus of ICIPE, Nairobi. The plants were uprooted after 45 days to gain leaves and roots. The samples were cleaned in streaming water and then dried by air in a ventilated hood in the lab to wipe the moisture before extraction.

\section{Chemicals and reagents}

All the analytical reference mixtures involving isoschaftoside, 2-glucosylvitexin, 6-glucosylvitexin-, isovitexin, vitexin, naringenin, and apigenin were of analytical grade. Other utilized analytical chemical reagents were naturstoffreagenz $\mathrm{A}$, normal silica gel, $\mathrm{C}_{18}$ silica gel, silica gel/TLC-plates, and silica gel $\mathrm{C}_{18}$ TLCplates. While organic solvents, namely; methanol, ethyl acetate, formic acid, sulphuric acid, hexane, and butanol, were all gained from Sigma Aldrich, USA.

\section{Instrumentation}

A high-performance liquid chromatography (HPLC) comprising a quaternary pump, column compartment, autosampler, and variable wavelength photodiode array detector (Data system, version 1.24 ACE, Shimadzu Corporation England) was utilized. An analytical ACE, RP- $\mathrm{C}_{18}$ column $(4.6 \mathrm{~mm}$ i.d. $\times 2500 \mathrm{~mm}, 5 \mu \mathrm{m}$ particle size) and a preparative ACE, RP-C ${ }_{18}$ column $(10 \mathrm{~mm}$ i.d. $\times 2500$ $\mathrm{mm}, 5 \mu \mathrm{m}$ particle size) (Hichrom LTD, England) were utilized on the process of analysis and separation. The mobile phase comprised formic acid in water (solvent $\mathbf{A}$ ) and methanol (solvent B). A seven-step gradient analysis for a total run time of $65 \mathrm{~min}$ was utilized as follows: beginning with $95 \%$ solvent $\mathrm{A}$ and $5 \%$ solvent $\mathbf{B}$, enhancing to $15 \%$ solvent $\mathbf{B}$ over $3 \mathrm{~min}$, then $25 \%$ solvent 
B over $10 \mathrm{~min}$, to $30 \%$ solvent $\mathbf{B}$ over $20 \mathrm{~min}$, to $95 \%$ solvent $\mathbf{B}$ over $13 \mathrm{~min}$ and finally for $7 \mathrm{~min} 5 \%$ solvent $\mathbf{B}$. The column compartment was kept at $20^{\circ} \mathrm{C}$ utilizing 10 $50 \mu 1$ injection volumes. The analytes were observed with PDA detection at between 225-350 nm.

The Liquid Chromatography-Mass Spectrometer utilized a quaternary LC pump (Model 1200) coupled to an Agilent MSD 6120-Single quadrupole mass spectrometer with an electrospray source. A Zorbax Eclipse Plus $\mathrm{C}_{18}$ column $(4.6 \times 100 \mathrm{~mm}$ i.d., $3.5 \mu \mathrm{m}$ particle size $)$ and a Zorbax narrow bore SB-C 18 RRHT $(2.1 \times 50 \mathrm{~mm}$ i.d, $1.8 \mu \mathrm{m}$ particle size) (Agilent Technologies, USA) were applied in the analysis. The mobile phase was solvent $\mathbf{A}$ : $1 \%$ formic acid in $\mathrm{H}_{2} \mathrm{O}$ and solvent $\mathbf{B}$ : $1 \%$ formic acid in $\mathrm{MeOH}$. Analysis conditions, including a three-step isocratic analysis for a total run time of $29.91 \mathrm{~min}$, were utilized as follows; beginning with $75 \%$ solvent $\mathbf{A}$ and $25 \%$ solvent $\mathbf{B}$, enhancing to $100 \%$ solvent $\mathbf{B}$ over $25 \mathrm{~min}$, then back to $25 \%$ solvent $\mathbf{B}$ over $2.9 \mathrm{~min}$. Injection volumes were 10-30 $\mu \mathrm{l}$, and signals were needed in full-scan positive-ion mode utilizing a 100 to $800 \mathrm{~m} / \mathrm{z}$ scan range.

Nine seemingly uncontaminated samples making concentrations higher than $0.001 \%$ in the plants were examined by LC-MS to ascertain their respective masses. LC-MS data were output utilizing a Hewlett-Packard 1090 photodiode array detector (Agilent Technologies) and a Perkin-Elmer SCIEX API III triple-quadrupole mass spectrometer (Perkin-Elmer, Toronto, Ontario, Canada) completed with an ion spray fount (ISV=5500, orifice voltage $=50$ ) in positive ion mode. Multiple reactions observing mode was utilized, observing the mass of the molecular (parent) ions in the first quadrupole (Q1) and scanning for the fragmented ions and flavonoids (daughter ions) in the third quadrupole (Q3). Argon was utilized as the collision gas, and nitrogen was utilized as the nebulizer gas and orifice curtain. The system was completed with a Synergi $4 \mu$ Hydro-RP $80 \AA(250 \times 2 \mathrm{~mm})$ column fitted with a $4.0 \times 3.0 \mathrm{~mm}$ i.d. guard column (Phenomenex) at a flow rate of $1 \mathrm{ml} / \mathrm{min}$. The mobile phase was Solvent A: $0.1 \%$ formic acid in $\mathrm{H}_{2} \mathrm{O}$ and Solvent B: $0.1 \%$ formic acid in $\mathrm{MeOH}$. The analysis included a five-step gradient analysis for a total run time of $25 \mathrm{~min}$ and was utilized as follows; beginning with $90 \%$ solvent $\mathbf{A}$ and $10 \%$ solvent $\mathbf{B}$, enhancing to $50 \%$ solvent B over $15 \mathrm{~min}$, then $80 \%$ solvent B over $5 \mathrm{~min}$ to $95 \%$ solvent $\mathbf{B}$ over $2 \mathrm{~min}$ and finally isocratic for $3 \mathrm{~min}$. The injection volume was $20 \mu \mathrm{l}$, and the scanning wavelength ranged from 190-800nm. Both positive and negative ions between $\mathrm{m} / \mathrm{z}, 100$ and $\mathrm{m} / \mathrm{z}, 1415$ were monitored.

\section{Laboratory procedures \\ Extraction}

Utilizing a WTC binder 7200 drying oven, air-dried roots and leaves of $C$. arietinum $\mathrm{L}$. and $V$. radiata $\mathrm{L}$. were further dried at temperatures of $40^{\circ} \mathrm{C}$ for 48 hours. Each plant's brittle, dry material was ground in Retsch $(\mathrm{GmbH}$ 5667 HAAN West-Germany) grinder, weighed (Table 1), then distilled with $50: 50 \mathrm{MeOH} / \mathrm{CH}_{2} \mathrm{Cl}_{2}$ at room temperature for 3 days in the ratio of one gram herbage: 7.5 $\mathrm{ml}$ solvent. Filtered to separate the filtrates from the residue, then the residual extraction was repeated twice utilizing the same solvent system. The filtrates were evaporated in vacuo and weighed. Each distillate was examined utilizing TLC and HPLC and then purified utilizing HPLC.

\section{Fractionation and isolation}

TLC analysis was implemented on silica plate (DCAlufolien-Kieselgel $25 \mathrm{~F}_{254 \mathrm{~nm}}$ ), and $\mathrm{C}_{18}$ (Alugram RP$\left.18 \mathrm{w} / \mathrm{UV}_{254}\right)$ utilizing mobile phase consisting of EtOAC$\mathrm{H}_{2} \mathrm{O}-\mathrm{HCO}_{2} \mathrm{H}$ (18:1:1), Hex-EtOAC (20:80 and 80:20). The mixtures were viewed under UV light and visualized after spraying with $5 \%$ sulphuric acid in methanol to increase spot detection. Then the TLC plates were dried at oven temperatures ranging between $80-100^{\circ} \mathrm{C}$.

Other solvent systems were examined in a bid to build up a column chromatography system to fractionate the constituents present in the distillate, and the mobile phase representing a better separation was picked out. The purifications of fractions were further performed by highperformance liquid chromatography (HPLC).

\section{Preliminary experiments}

Fingerprint chromatographic profiles of the two types of C. arietinum, Kabuli and Desi Chickpeas, were examined utilizing TLC plates and HPLC instruments. A comparison of the biochemical composition of aqueous extracts in the roots and leaves of the two plants was carried out based on the variation in concentration and existence or absence of secondary metabolites. Also, HPLC fingerprint profiles of $V$. radiata leaves and roots were gained.

A medium normal phase column of $C$. arietinum leaves was eluted utilizing other solvent systems of various concentrations and polarity from hexane, EtOAc, $\mathrm{CH}_{2} \mathrm{Cl}_{2}$, $\mathrm{MeOH}$ then Water to ascertain an appropriate solvent system for extracting polar mixtures from the legumes. TLC and HPLC examined the results. The solvent system at which polar secondary metabolites were eluted at substantial concentration was recommended for utilization in extraction.

On the other hand, the extraction of $C$. arietinum from leaves was performed by suspending the leaves in water and partitioning them with hexane, ethyl acetate, then butanol. Each distillate was examined utilizing TLC and HPLC to determine the best solvent giving a better separation of the mixtures, and utilized to assess the proportional quantities of various elements in the extracts.

\section{Description of segregated mixtures}

Isolates from each plant part were given codes in the order of their elution time/retention time. For example, CAL 1 is the first segregated peak from the crude distillate of $C$. arietinum leaf. The first two letters are the abbreviation of the plant's botanical name, and the third letter is the abbreviation of the part of the plant from which the segregation was gained.

The segregated mixtures were described utilizing the HPLC by analyzing the peak fineness of the segregated peaks, comparing their UV maximum wavelength 
absorbance with standards and one to another, and utilizing retention time proportional to that of known standards. LCMS analysis was utilized to gain molecular ions and characteristic fragments utilizing MS data of the legumes' pure extractable.

A chemical test for flavonoid glycosides was carried out utilizing filter papers dipped in an ethanol solution of the individual mixture and then exposed to ammonia vapor. The formation of yellow spots on filter paper showed the existence of flavonoid glycoside (Ahmed 2007).

Utilizing the HPLC, the segregated mixtures' retention times and UV $\lambda_{\max }$ were compared with known flavonoid glycosides to determine their nature at a LOD of $0.25 \mu \mathrm{g} / \mathrm{L}$ compared to the chemical tests for flavonoid glycoside with a higher LOD.

\section{Spectrophotometric description}

The initial spectral scan of phenolics from nine samples of the leaves and roots of $C$. arietinum and $V$. radiata was carried out by combining the data from PDA and MS to permit easy and efficient identification. Three screening schemes were utilized as follows:

Firstly, where reference mixtures were accessible as standards, the existence or absence of a particular biophenol was appraised by comparing retention time and UV-visible spectra with that of the reference. Where the retention times were noticed to be alike, co-injection and comparison of the UV-visible spectra were carried out. Molecular mass data further verified the existence.

Secondly, when reference mixtures were not accessible, the TIC traces in positive mode at soft ionization and strong ionization conditions were monitored for relevant, suitable pseudomolecular ions $[\mathrm{M}+\mathrm{H}]^{+}$. Verification was carried out by analyzing UV-visible spectra and mass spectral fragmentation data at the expected elution time, depending on pre-identified mixtures in the sample, the structure of the target mixture, and the literature data.

Thirdly, major peaks in TIC and UV chromatograms that were not distinguished by the other screening processes were screened for novel mixtures by generating mass spectra. In all, screening was performed for nine biophenols from different classes. The principal objective was to show the power of mixed utilization of HPLC-PDA and ESI-MS in profiling legume extracts.

Samples were injected into an LC-MS system, allowing spectral analysis followed by mass ascertainment to ascertain the moieties attached to the glycoside.

\section{RESULTS AND DISCUSSION}

\section{Method validation and preliminary results Sample harvest}

The ground leaves and roots of the $C$. arietinum and $V$. radiata plants were weighed and noted. Further, the parts of plants were distilled utilizing $50 / 50 \mathrm{MeOH} / \mathrm{CH}_{2} \mathrm{Cl}_{2}$ and evaporated in vacuo, then noted (Table 1).

The harvest was not optimal for $V$. radiata because of the attack of cat worms on the plantation. The distillate weights above were utilized to ascertain the capacity and amount of packing material used in column chromatography.

\section{Fingerprints}

Two different chickpea grains were grown separately on the field; the plantations were similar in the first 30 days. But on flowering, the Desi (SCP 1) chickpea owned purple flowers, while Kabuli (SCP 2) chickpeas had white flowers. Figure 2 shows TLC and HPLC chromatograms of the other parts of the plants.

Table 1. Harvest of the crude sample and extracts

\begin{tabular}{lccc}
\hline Sample name & $\begin{array}{c}\text { Powder } \\
\text { (grams) }\end{array}$ & $\begin{array}{c}\text { Distillate } \\
\text { (grams) }\end{array}$ & \% harvest \\
\hline C. arietinum leaves & 346.3 & 71.6 & 21 \\
C. arietinum roots & 59.0 & 6.3 & 11 \\
V. radiata leaves & 275.8 & 25.8 & 10 \\
V. radiata roots & 67.7 & 3.2 & 5 \\
\hline
\end{tabular}

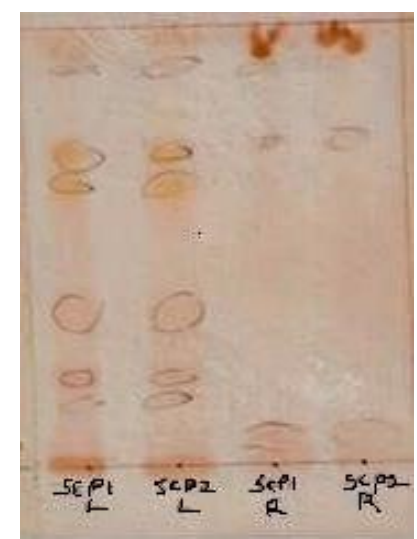

Figure 2.A. TLC card I, comparison of composition in Cicer arietinum leaves and roots (SCP $1 \&$ SCP2)

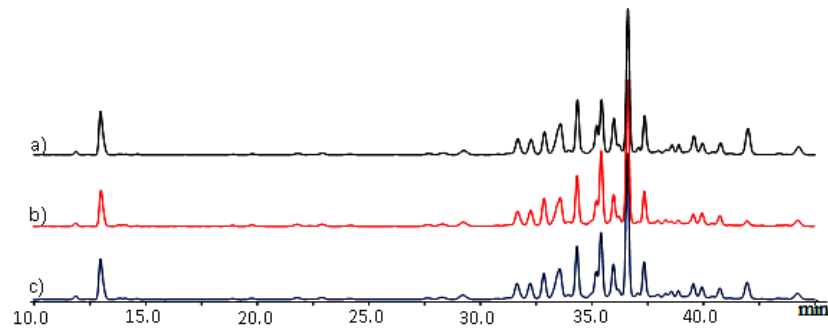

Figure 2.B. HPLC Cicer arietinum leaves profiles of a) Kabuli (SCP 2);b) Desi (SCP1); c) Mixture

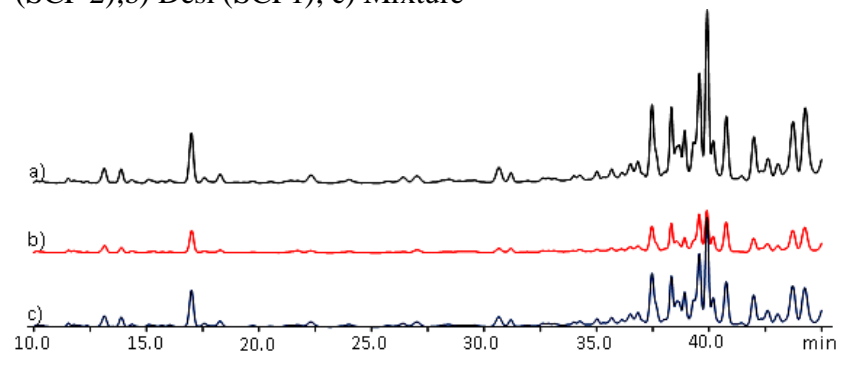

Figure 2.C. HPLC Cicer arietinum roots profiles of; a) Kabuli (SCP 2); b) Desi (SCP1); c) mixture 
There were varieties in the amounts of mixtures found in the two plants, similarity in the TLC retention factors of eluted mixtures, and fingerprint HPLC profiles between the two types of plants showed the same aqueous chemical elements. Therefore, the resembling plant parts were mingled and examined as leaves and roots of $C$. arietinum.

Likewise, to view the aqueous secondary metabolites found in the $V$. radiata plant, see the HPLC profile of leaves and roots at $270 \mathrm{~nm}$ and $350 \mathrm{~nm}$ absorbance below (Figures 3.A and B).

Obviously, few are the polar mixtures in substantial amounts in the two parts of the plant; $V$. radiata. Even though it was likely to segregate the present mixtures utilizing the HPLC, the process was complicated because the plant possesses a raged profile (especially the root profile; the $270 \mathrm{~nm}$ profile is very dissimilar from the 350 $\mathrm{nm}$ one) mixture is in a very small amount.

\section{Solvent system}

Other solvent systems were examined for extraction to ensure maximum collection of the polar secondary metabolite from the plants. A $9.6 \mathrm{~g}$ portion of $C$. arietinum leaves had been distilled utilizing $80 / 20 \mathrm{MeOH} / \mathrm{H}_{2} \mathrm{O} .1 \mathrm{~g}$ of the distillate was suspended in water and partitioned with hexane, ethyl acetate, and butanol. The weights of fractions were noted (Table 2).

Alongside the crude sample, the separation in four fractions was examined on silica gel $\mathrm{C}_{18}$ TLC-plate (Figures 4.A), mobile phase; EtOAc- $\mathrm{H}_{2} \mathrm{O}-\mathrm{HCO}_{2} \mathrm{H}$ 18:1:1. Further, HPLC chromatograms (Figure 4.B) were gained.

Likewise, $1.4 \mathrm{~g}$ of $C$. arietinum leaves distillate was liquefied in $50 / 50 \mathrm{MeOH} / \mathrm{CH}_{2} \mathrm{Cl}_{2}$. The soluble part of the sample (1.0 g) was fixed in $2 \mathrm{~g}$ of silica gel. Utilizing a 1/30 sample: silica gel ratio, a 42.3 g capacity column was packed with $31.0 \mathrm{~g}$ silica gel liquefied in hexane. The mobile phase varied from hexane, ethyl acetate, dichloromethane, and methanol to water. 30 fractions of 20 $\mathrm{ml}$ each were gained. A TLC $\mathrm{C}_{18}$ card was spotted after fractionation and utilizing the mobile phase; EtOAc- $\mathrm{H}_{2} \mathrm{O}$ $\mathrm{HCO}_{2} \mathrm{H}$ 18:1:1 spots were developed (Figure 5.A). Eight fractions were pooled as shown on the TLC card below and then examined utilizing the HPLC (Figure 5.B).

These experiments found no separation of mixtures utilizing neither fractionating funnel nor normal phase column chromatography. From the hexane fraction, no polar mixtures were noticed. While in the butanol and water fractions, all the mixtures existing in the crude sample were found at low amounts. Ethyl acetate yielded an enhanced concentration of some mixtures existing in the original sample.

From the column chromatography, it was examined that methanol dichloromethane solvent systems liquefy most polar mixtures. Therefore, extraction of the samples was carried out utilizing 50/50 $\mathrm{MeOH} / \mathrm{CH}_{2} \mathrm{Cl}_{2}$, and column chromatography was utilized for fractionation and purification of the samples. It was suggested that before utilizing the HPLC for the segregation of peaks, column chromatography should be carried out at least twice for every sample for purification, enhanced amounts of present mixtures, and higher resolution.

\section{Spectroscopic study of reference biophenols}

A series of flavonoid standards (Figure 6), representative of other flavonoid groups previously reported in allelopathic $D$. uncinatum and other legumes, utilizing HPLC-PDA and RP-LC-ESI-MS, were observed to determine their structure/spectra. From HPLC-PAD, various correlations between structure and UV spectrum were distilled (Table 3).

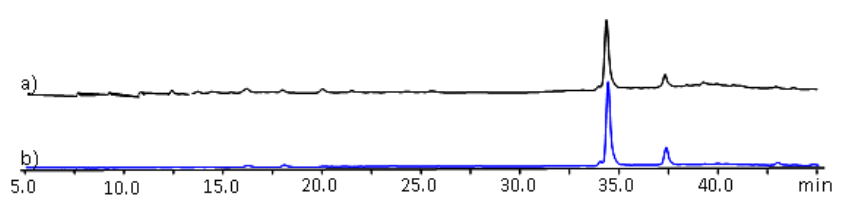

Figure 3.A. HPLC profiles of V. radiata leaves at a) at $270 \mathrm{~nm}$ absorbance, b) at $350 \mathrm{~nm}$ absorbance.

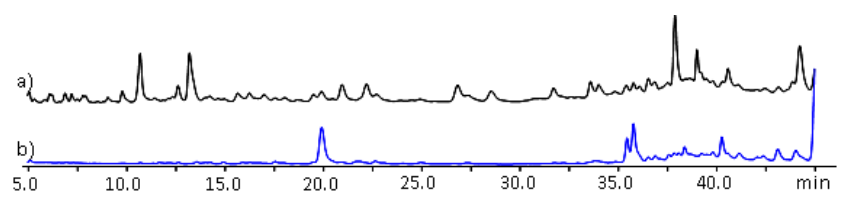

Figure 3.B. HPLC profiles of V. radiata roots at a) at $270 \mathrm{~nm}$ absorbance, b) at $350 \mathrm{~nm}$ absorbance.

Table 2. Weights of $1 \mathrm{~g}$ Cicer arietinum leaf partitioned

\begin{tabular}{lll}
\hline Fraction & Weight in $(\mathbf{m g})$ & Percentage weight $(\%)$ \\
\hline Hexane & 27.8 & 2.8 \\
Ethyl Acetate & 50.0 & 5 \\
Butanol & 20.0 & 2 \\
Water & 25.1 & 2.5 \\
\hline
\end{tabular}

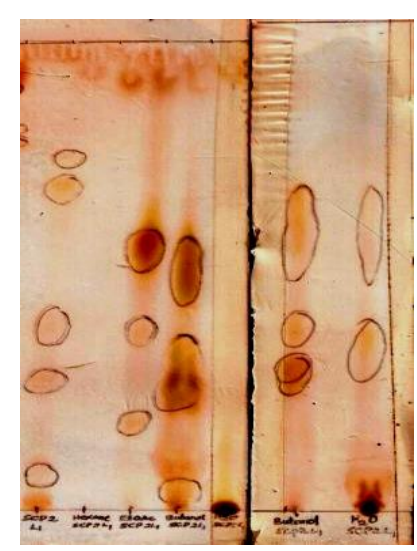

Figure 4.A. TLC card II, C. arietinum leaf fractionation utilizing a fractionating funnel

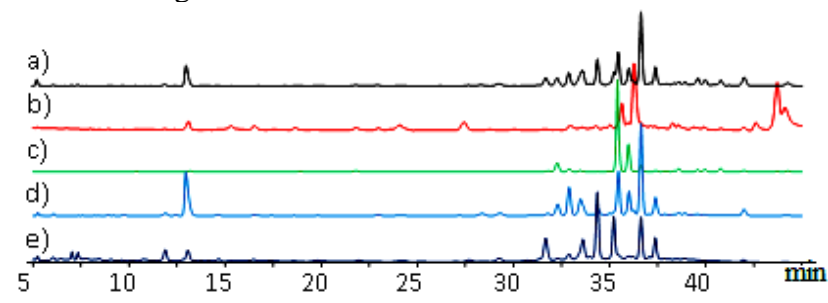

Figure 4.B. Fractionating funnel's HPLC profile at $270 \mathrm{~nm}$ of Cicer arietinum leaf a) Crude sample; b) Hexane fraction; c) Ethyl acetate fraction; d) Butanol fraction; e) Water fraction. 


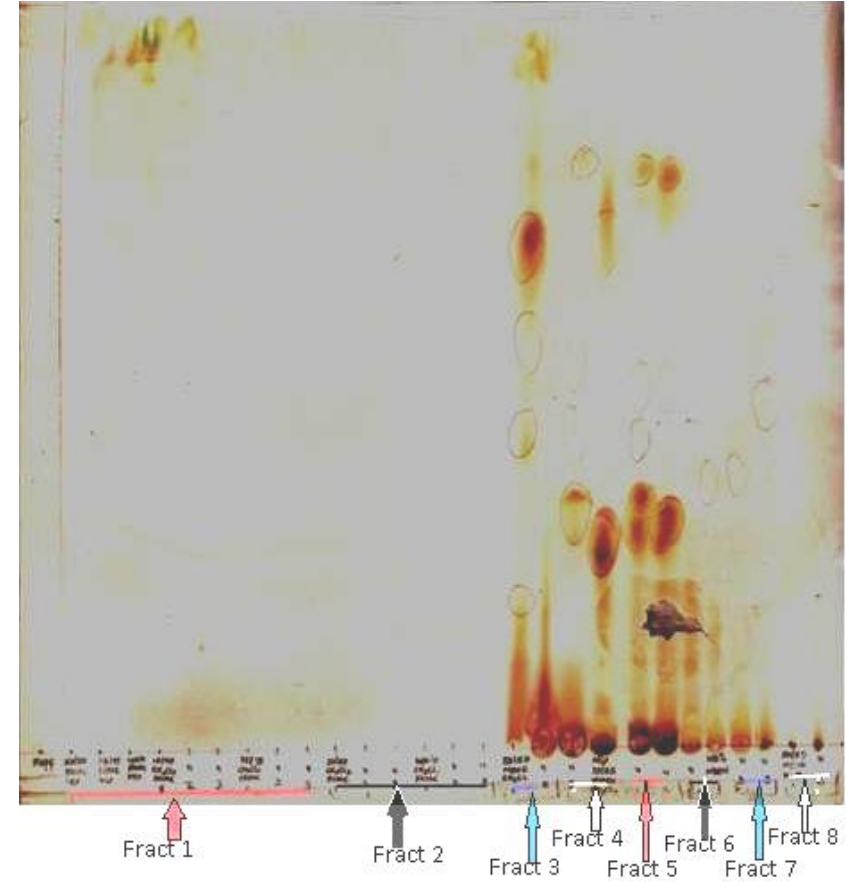

Figure 5.A. TLC card III, Preliminary column chromatography fractionation of Cicer arietinum leaf

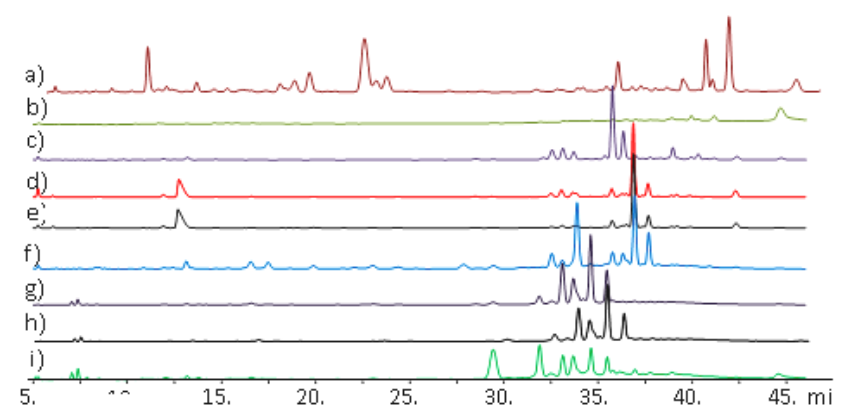

Figure 5.B. Preliminary analysis utilizing HPLC profiles at 270 $\mathrm{nm}$ of Cicer arietinum leaves fractions a) Crude sample; b) Fraction 1 c) Fraction 2; d) Fraction 3; e) Fraction 4; f) Fraction 5; g) Fraction 6; h) Fraction 7; Fraction 8

Table 3. Reference biophenols

\begin{tabular}{llclc}
\hline Cording & $\begin{array}{c}\text { Flavonoid } \\
\text { standards }\end{array}$ & $\begin{array}{c}\text { Retention } \\
\text { time } \mathbf{T}_{\mathbf{R}} \\
(\mathbf{m i n})\end{array}$ & $\begin{array}{c}\text { Maximum } \\
\text { absorbance } \\
\left(\lambda_{\max }\right)(\mathbf{n m})\end{array}$ & $\begin{array}{c}\text { Molecular } \\
\text { weight } \\
{[\mathbf{M}]^{+}}\end{array}$ \\
\hline 1 & Genistein & 8.89 & $212,225,229,280$ & 270 \\
2 & 6-glucosylvitexin & 17.83 & $219,239,334$ & 594 \\
3 & Isoschaftoside & 21.99 & $218,239,270,336$ & 564 \\
4 & Vitexin & 24.64 & $214,267,343$ & 432 \\
5 & 2-glucosylvitexin & 26.80 & $207,239,268,334$ & 594 \\
6 & Isovitexin & 30.51 & $214,239,267,343$ & 432 \\
7 & Naringenin & 36.68 & 213,288 & 273 \\
8 & Luteolin & 38.93 & $225,256,292,349$ & 286 \\
9 & Apigenin & 41.74 & $212,238,267$ & 270 \\
10 & Quercetin dihydrate & 50.98 & 238,258 & 302 \\
\hline
\end{tabular}

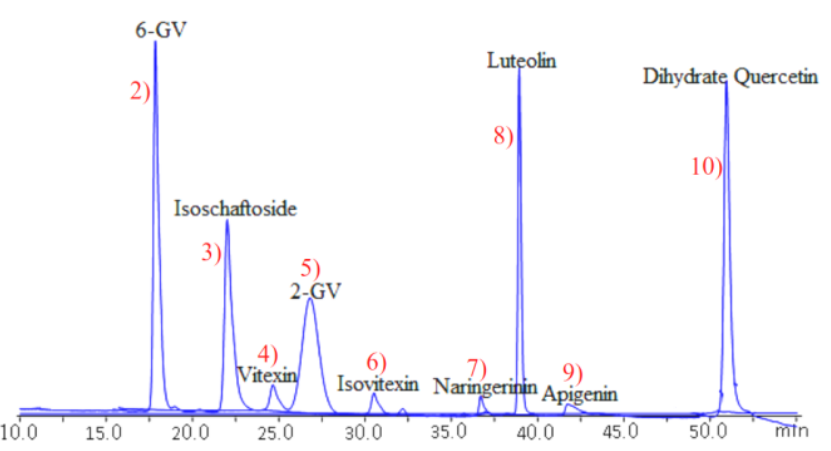

Figure 6. A simultaneous HPLC chromatogram was obtained with a photodiode array detector set at $350 \mathrm{~nm}$ (A); Peak identification was listed in Table 3 (B)

The most influential flavonoids are the $\lambda_{\max }$ (a band I), and it increases in the series: flavones (apigenin) < flavonol (quercetin). The $\lambda_{\max }$ also indicated the substitution within the same class for glucosylvitexins, vitexin, and isovitexin. The permeation $\lambda_{\max }$ was not affected in isomers of the same group (e.g., vitexin and isovitexin) Table 3 .

\section{Fractions and isolates of secondary metabolites} Cicer arietinum roots

Column chromatography I. Flash fractionation column chromatography was utilized to fractionate $C$. arietinum roots (Table 4). The fractions were examined by HPLC (Figure 7) obtained with a photodiode array detector set at $270 \mathrm{~nm}$.

No polar mixtures were examined using mobile phases (d, e, f, and g). The separation was poor in fraction (h), where the mixtures were not concentrated. Still, where the concentration was better, isolation of individual peaks would be complicated because the mixtures were very close to each other. In fractions ( $\mathrm{I}, \mathrm{j}, \mathrm{k}$, and $\mathrm{l}$ ), the clarity and concentration of the mixtures were good. Therefore, it was suggested that a smaller column comprising a mixture of the four fractions should be mounted to purify the fractions further.

Table 4. Fractionation on the $1^{\text {st }}$ column of $C$. arietinum roots

\begin{tabular}{llccc}
\hline \multicolumn{2}{l}{ Fraction Solvent System } & $\begin{array}{c}\text { \% Conc. of } \\
\text { extraction } \\
\text { solvent }\end{array}$ & $\begin{array}{c}\text { Weight of } \\
\text { dry Sample } \\
\text { in (g) }\end{array}$ & $\begin{array}{c}\text { Percentage } \\
\text { weight (\%) }\end{array}$ \\
\hline Crude & - & - & 5.5 & \\
0 & EtOAc & 100 & 1.77 & 32.2 \\
1 & $\mathrm{EtOAc}$ & 100 & 0.18 & 3.3 \\
2 & $\mathrm{EtOAc} / \mathrm{CH}_{2} \mathrm{Cl}_{2}$ & 75 & 0.06 & 1.1 \\
3 & $\mathrm{EtOA}_{2} / \mathrm{CH}_{2} \mathrm{Cl}_{2}$ & 50 & 0.05 & 0.9 \\
4 & $\mathrm{EtOA}_{\mathrm{C}} / \mathrm{CH}_{2} \mathrm{Cl} 2$ & 25 & 0.03 & 0.5 \\
5 & $\mathrm{CH}_{2} \mathrm{Cl}_{2}$ & 100 & 0.05 & 0.9 \\
6 & $\mathrm{CH}_{2} \mathrm{Cl}_{2} / \mathrm{MeOH}_{2}$ & 95 & 0.24 & 4.4 \\
7 & $\mathrm{CH}_{2} \mathrm{Cl}_{2} / \mathrm{MeOH}$ & 90 & 0.86 & 15.6 \\
8 & $\mathrm{CH}_{2} \mathrm{Cl}_{2} / \mathrm{MeOH}$ & 80 & 1.27 & 23.1 \\
9 & $\mathrm{CH}_{2} \mathrm{Cl}_{2} / \mathrm{MeOH}$ & 50 & 1.40 & 25.5 \\
10 & $\mathrm{CH}_{2} \mathrm{Cl}_{2} / \mathrm{MeOH}$ & 25 & 0.30 & 5.5 \\
11 & $\mathrm{MeOH}_{12}$ & 100 & 0.17 & 3.1 \\
12 & $\mathrm{MeOH}_{2} / \mathrm{H}_{2} \mathrm{O}$ & 50 & & \\
13 & $\mathrm{H}_{2} \mathrm{O}$ & 100 & & \\
\hline
\end{tabular}




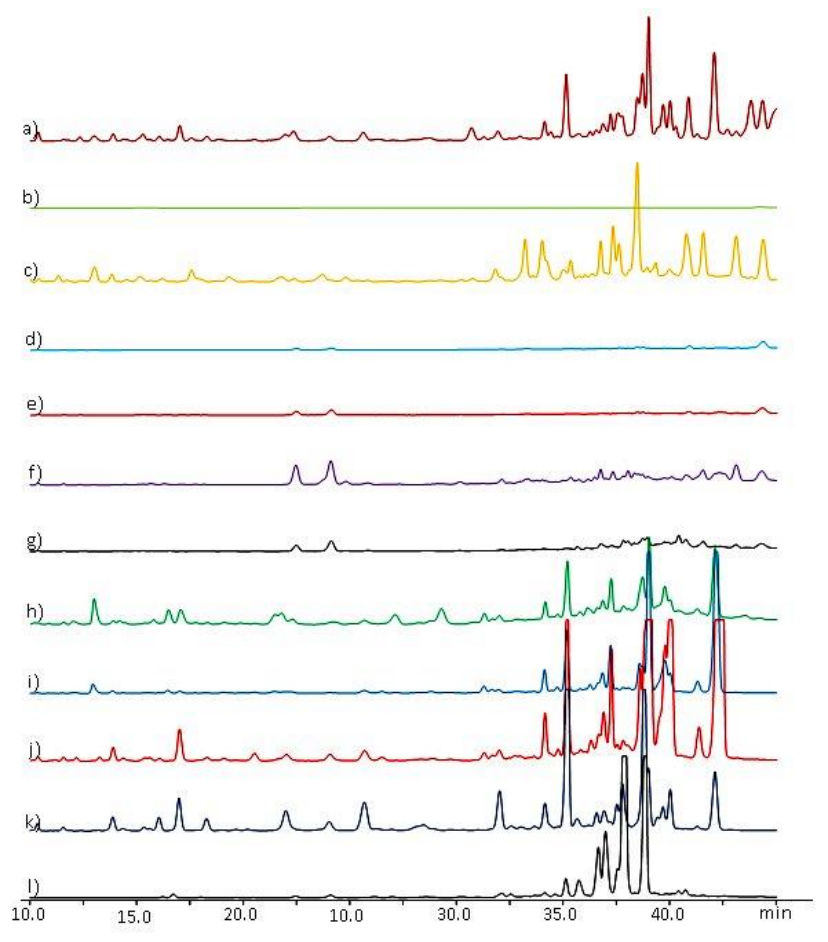

Figure 7. HPLC profiles of $C$. arietinum roots fractions from 1st column. a) Crude sample; b) $100 \%$ EtOAc-0; c) $100 \%$ EtOAc-1; d) $\mathrm{EtOAc} / \mathrm{CH}_{2} \mathrm{Cl}_{2} \quad 75 / 25 ;$ e) $\mathrm{EtOAc} / \mathrm{CH}_{2} \mathrm{Cl}_{2} \quad 50 / 50 ;$ f) $\mathrm{EtOAc} / \mathrm{CH}_{2} \mathrm{Cl}_{2} 25 / 75$; g) $100 \% \mathrm{CH}_{2} \mathrm{Cl}_{2}$;h) $\mathrm{MeOH} / \mathrm{CH}_{2} \mathrm{Cl}_{2} 25 / 75$; i) $\mathrm{MeOH} / \mathrm{CH}_{2} \mathrm{Cl}_{2} 50 / 50$; j) $\left.\mathrm{MeOH} / \mathrm{CH}_{2} \mathrm{Cl}_{2} 80 / 20 ; \mathrm{k}\right) \mathrm{MeOH} / \mathrm{CH}_{2} \mathrm{Cl}_{2}$ 90/10; 1) $\mathrm{MeOH} / \mathrm{CH}_{2} \mathrm{Cl}_{2} 95 / 5$

Column chromatography II. A second $600 \mathrm{ml}$ column was packed, and 4 fractions each of $20 \mathrm{ml}$ were eluted utilizing 95/5, 90/10, 85/15, 80/20, then $50 / 50$ $\mathrm{MeOH} / \mathrm{CH}_{2} \mathrm{Cl}_{2}$, respectively. Each fraction was spotted on silica gel/TLC cards (Figure 8). The spots were developed utilizing a mobile phase comprising EtOAc- $\mathrm{H}_{2} \mathrm{O}-\mathrm{HCO}_{2} \mathrm{H}$ (18:1:1). Further HPLC profiles were obtained with a photodiode array detector set at $270 \mathrm{~nm}$ (Figure 9) of 6 fractions pooled as shown on the TLC card were gained on the PDA detector. The better resolution was examined in fractions d), e), and f). Utilizing HPLC, well-resolved peaks of substantial concentration in the fractions were suggested for isolation.

Description of isolates. Utilizing an HPLC on a PDA detector at $270 \mathrm{~nm}$ and a preparative $\mathrm{RP}-\mathrm{C}_{18}$ column (10 $\mathrm{mm}$ i.d. $\times 250 \mathrm{~cm}, 5 \mu \mathrm{m}$ particle size), six fractions were gained, and weights were noted (Table 5). HPLC profiles on the analytical column were obtained with a photodiode array detector set at $270 \mathrm{~nm}$ (Figure 10).

Utilizing the LC-MS, TIC traces in positive mode at soft ionization and strong ionization conditions were monitored, and relevant pseudomolecular ions $[\mathrm{M}+\mathrm{H}]^{+}$ were gained. Results are presented in Table 5.

Analysis utilizing the RP-HPLC showed that all the six extracts; CAR 1, CAR 2, CAR 3, CAR 4, CAR 5, and CAR 6 , presented characteristics of single peaks at their respective retention times. Meaning that they were good enough to be described utilizing the LC-MS. CAR 5 and CAR 6 were enough for further analysis.

On further analysis, utilizing the LC-MS, three of the mixtures that TIC scans presented with single peaks could be distinguished. Still, only CAR 5had a flavonoid aglycone based on the Phenol-Explorer database (Anon 2012) was distinguished in this study.

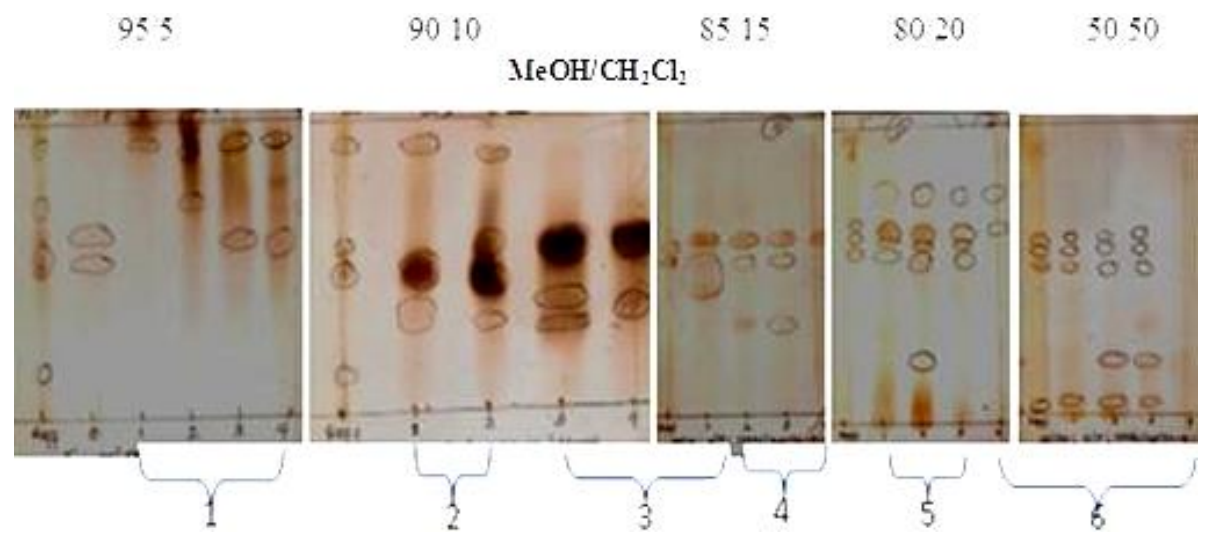

Figure 8. TLC card IV, C. arietinum root fractions from 2nd column chromatography

Table 5. HPLC, LC-MS, and Flavonoid test analysis of Cicer arietinum root distillate

\begin{tabular}{|c|c|c|c|c|c|c|c|}
\hline Fraction & $\begin{array}{c}\text { Weight in } \\
\text { (mg) }\end{array}$ & $\begin{array}{c}\% \text { of distil- } \\
\text { late }\end{array}$ & $\begin{array}{c}\text { Retention } \\
\text { Time (min) }\end{array}$ & $\begin{array}{c}\mathbf{U V} \\
\lambda \max (\mathbf{n m})\end{array}$ & {$[\mathbf{M}]^{+}$} & Purity & Ammo-nia test \\
\hline$\overline{\text { CAR } 1}$ & 0.34 & 0.005 & $16.6 \sim 17.0$ & $222,273,318$ & $470 / 590$ & Impure & -ve \\
\hline CAR 2 & 0.70 & 0.010 & $27.5 \sim 27.9$ & 224,272 & 484 & Impure & -ve \\
\hline CAR 3 & 0.30 & 0.005 & $27.8 \sim 28.6$ & $223,239,262$ & 472 & Pure & -ve \\
\hline CAR 4 & 0.22 & 0.004 & $31.5 \sim 31.8$ & 228,260 & 484 & Pure & -ve \\
\hline CAR 5 & 13.54 & 0.215 & $34.6 \sim 35.0$ & 236,254 & 430 & Pure & $+\mathrm{ve}$ \\
\hline CAR 6 & 13.06 & 0.207 & $38.2 \sim 38.6$ & $224,239,260,325$ & $390 / 468$ & Impure & -ve \\
\hline
\end{tabular}



Cicer arietinum leaves

Column chromatography I. A $1020 \mathrm{ml}$ capacity column was packed, and 40 fractions, $200 \mathrm{ml}$ each, of $C$. arietinum leaves were collected (Table 6) with the varying polarity of the eluting solvent from hexane to methanol. The mobile phase was altered only at the time there was no more examinable decomposition following analysis by TLC.

Utilizing mobile phase EtOAc- $\mathrm{H}_{2} \mathrm{O}-\mathrm{HCO}_{2} \mathrm{H}$ 18:1:1 (Figure 11.A), the spots were spread, then a repeat of the first 27 fractions was carried out utilizing EtOAc: Hex; 80:20 (Figure 11.B).

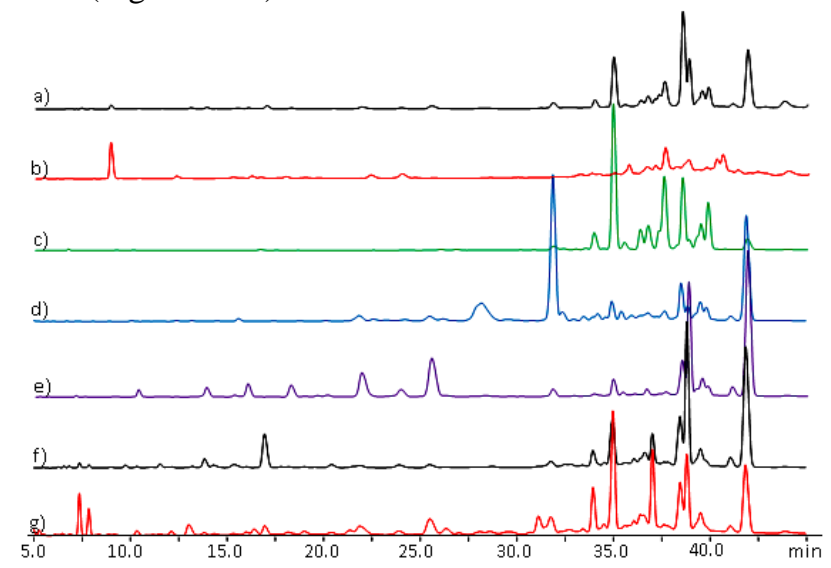

Figure 9. HPLC roots profiles of fractions from Cicer arietinum 2nd columncrude sample; b) Fraction 1; c) Fraction 2; d) Fraction 3 ; e) Fraction 4;f) Fraction 5; i) Fraction 6

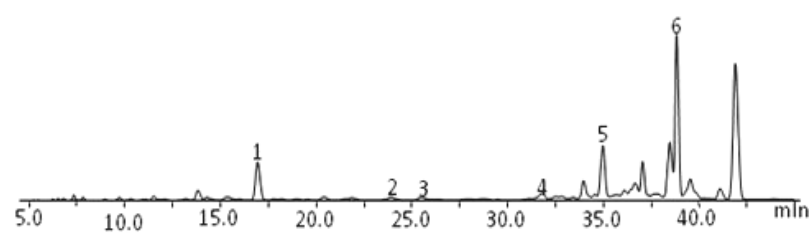

Figure 10. Segregated mixtures from Cicer arietinum roots
Table 6. Fractionation on the $1^{\text {st }}$ column of Cicer arietinum leaf

\begin{tabular}{|c|c|c|c|c|}
\hline \multicolumn{2}{|c|}{ Fraction Solvent system } & $\begin{array}{l}\text { Percentage } \\
\text { conc. }\end{array}$ & $\begin{array}{l}\text { Weight of dry } \\
\text { sample }\end{array}$ & $\begin{array}{c}\text { Percentage } \\
\text { harvest }\end{array}$ \\
\hline \multicolumn{2}{|c|}{$\overline{\text { CRUDE }}$} & & 54.33 & \\
\hline 1 & Hexane & 100 & 1.23 & 2.30 \\
\hline 2 & Hexane & 100 & 0.50 & 0.90 \\
\hline 3 & Hexane/EtOAc & 90 & 0.23 & 0.40 \\
\hline 4 & Hexane/EtOAc & 90 & 0.25 & 0.50 \\
\hline 5 & Hexane/EtOAc & 90 & 0.15 & 0.30 \\
\hline 6 & Hexane/EtOAc & 90 & 0.22 & 0.40 \\
\hline 7 & Hexane/EtOAc & 50 & 0.13 & 0.20 \\
\hline 8 & Hexane/EtOAc & 50 & 2.22 & 4.10 \\
\hline 9 & Hexane/EtOAc & 50 & 0.38 & 0.70 \\
\hline 10 & Hexane/EtOAc & 50 & 0.36 & 0.70 \\
\hline 11 & Hexane/EtOAc & 50 & 0.03 & 0.05 \\
\hline 12 & Hexane/EtOAc & 50 & 0.02 & 0.04 \\
\hline 13 & Hexane/EtOAc & 50 & 0.14 & 0.30 \\
\hline 14 & EtOAc & 100 & 0.05 & 0.09 \\
\hline 15 & EtOAc & 100 & 0.04 & 0.07 \\
\hline 16 & EtOAc & 100 & 0.08 & 0.15 \\
\hline 17 & EtOAc & 100 & 0.12 & 0.20 \\
\hline 18 & EtOAc & 100 & 0.23 & 0.40 \\
\hline 19 & EtOAc & 100 & 0.34 & 0.60 \\
\hline 20 & $\mathrm{EtOAc} / \mathrm{CH} 2 \mathrm{Cl} 2$ & 50 & 0.30 & 0.55 \\
\hline 21 & $\mathrm{EtOAc} / \mathrm{CH} 2 \mathrm{Cl} 2$ & 50 & 0.25 & 0.50 \\
\hline 22 & $\mathrm{EtOAc} / \mathrm{CH} 2 \mathrm{Cl} 2$ & 50 & 0.14 & 0.30 \\
\hline 23 & $\mathrm{CH} 2 \mathrm{Cl} 2$ & 100 & 0.04 & 0.07 \\
\hline 24 & $\mathrm{CH} 2 \mathrm{Cl} 2$ & 100 & 0.03 & 0.05 \\
\hline 25 & $\mathrm{CH} 2 \mathrm{Cl} 2$ & 100 & 0.01 & 0.02 \\
\hline 26 & $\mathrm{CH} 2 \mathrm{Cl} 2 / \mathrm{MeOH}$ & 90 & 0.02 & 0.04 \\
\hline 27 & $\mathrm{CH} 2 \mathrm{Cl} 2 / \mathrm{MeOH}$ & 90 & 0.04 & 0.07 \\
\hline 28 & $\mathrm{CH} 2 \mathrm{Cl} 2 / \mathrm{MeOH}$ & 90 & 3.63 & 6.70 \\
\hline 29 & $\mathrm{CH} 2 \mathrm{Cl} 2 / \mathrm{MeOH}$ & 80 & 4.70 & 8.70 \\
\hline 30 & $\mathrm{CH} 2 \mathrm{Cl} 2 / \mathrm{MeOH}$ & 80 & 5.21 & 9.60 \\
\hline 31 & $\mathrm{CH} 2 \mathrm{Cl} 2 / \mathrm{MeOH}$ & 80 & 5.31 & 9.80 \\
\hline 32 & $\mathrm{CH} 2 \mathrm{Cl} 2 / \mathrm{MeOH}$ & 80 & 5.40 & 9.90 \\
\hline 33 & $\mathrm{CH} 2 \mathrm{Cl} 2 / \mathrm{MeOH}$ & 80 & 2.74 & 5.0 \\
\hline 34 & $\mathrm{CH} 2 \mathrm{Cl} 2 / \mathrm{MeOH}$ & 50 & & \\
\hline 35 & $\mathrm{CH} 2 \mathrm{Cl} 2 / \mathrm{MeOH}$ & 50 & & \\
\hline 36 & $\mathrm{CH} 2 \mathrm{Cl} 2 / \mathrm{MeOH}$ & 50 & & \\
\hline 37 & $\mathrm{MeOH}$ & 100 & & \\
\hline 38 & $\mathrm{MeOH}$ & 100 & & \\
\hline 39 & $\mathrm{MeOH}$ & 100 & & \\
\hline
\end{tabular}

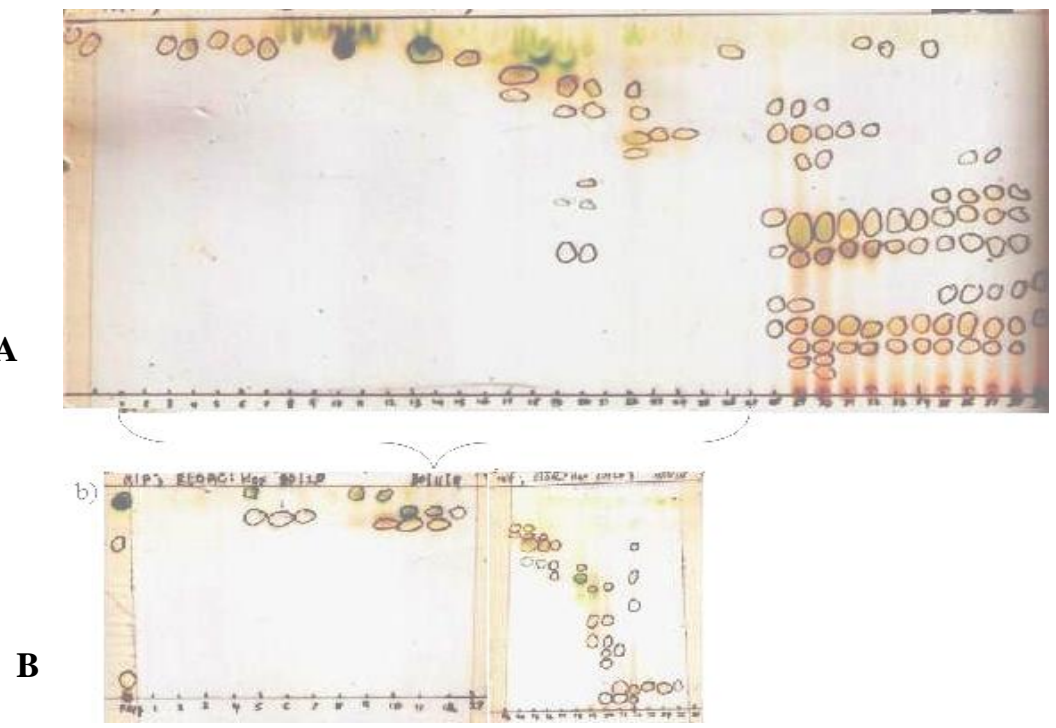

Figure 11.A-B. TLC cards V; Fractions from the $1^{\text {st }}$ column chromatography of Cicer arietinum leaf 


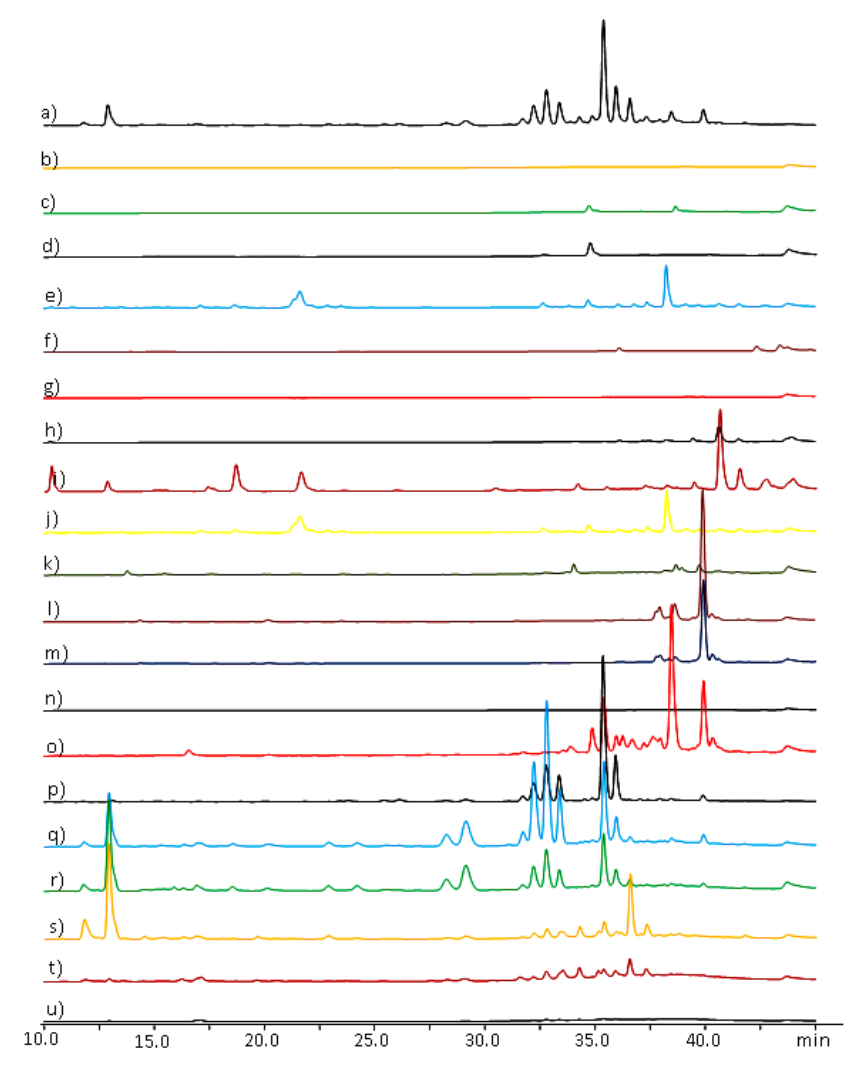

Figure 12. HPLC profiles of $1^{\text {st }}$ column chromatography of Cicer arietinum leaf. a) Crude sample; b) Fraction 2; c) Fraction 4; d) Fraction 6 ; e) Fraction 8 ; f) Fraction 10 ; g) Fraction 12 ; h) Fraction 14; i) Fraction 16; j) Fraction 18; k) Fraction 20; 1) Fraction 22; m) Fraction 24; n) Fraction 26; o) Fraction 28;p) Fraction 30; q) Fraction 32; r) Fraction 34; s) Fraction 36; t) Fraction38;u) Fraction 40

Only the even-numbered fractions on the TLC card were examined on HPLC and were obtained with a photodiode array detector set at $270 \mathrm{~nm}$ (Figure 12).

The mixtures were primarily eluted in fractions 29-33. Therefore, these fractions were pooled, dried, and a reversed-phase column packed and eluted with ethyl acetate, dichloromethane and methanol while slowly changing the percentage concentrations of solvents (Table 7).

Column chromatography II. The sample from fractions 29-33 weighing $23.4 \mathrm{~g}$ was fixed in $\mathrm{C}_{18}$ silica gel and a reversed-phase column packed and then eluted with ethyl acetate, dichloromethane and methanol while slowly varying the percentage concentrations of the solvent system. Results are presented in Table 7.

Fourteen fractions were spotted on silica gel TLC card IV, and spots were expanded utilizing mobile phase; EtOAc- $\mathrm{H}_{2} \mathrm{O}-\mathrm{HCO}_{2} \mathrm{H}$ 18:1:1 (Figure 13).

HPLC analysis of four was relatively similar to the 14 fractions, as shown on the TLC card (Figure 14).

The majority of the mixtures concerning the crude sample were accessible in fraction D with better separation. The fractions involving fractions 12,13 , and 14 had been eluted utilizing a mobile phase of concentration varying from $30 / 70$ to $40 / 60 \mathrm{MeOH} / \mathrm{CH}_{2} \mathrm{Cl}_{2}$. This fraction was suggested for further fractionation utilizing the HPLC.
Description of isolates. A shorter gradient elution technique was optimized from the original $65 \mathrm{~min}$ technique that lasted 49 minutes. 11 extracts were gained; Figure 15 shows the HPLC peak profile obtained with a photodiode array detector set at $270 \mathrm{~nm}$.

Table 7. Fractionation of Cicer arietinum leaf on the 2nd column chromatography

\begin{tabular}{|c|c|c|c|c|}
\hline Fraction & Solvent System & $\begin{array}{l}\text { Percen } \\
\text { Conc. }\end{array}$ & $\begin{array}{l}\text { Weight of } \\
\text { dry sample }\end{array}$ & $\begin{array}{l}\text { Percentage } \\
\text { Harvest }\end{array}$ \\
\hline 1 & EtOAc & 100 & 0.52 & 2.2 \\
\hline 2 & EtOAc & 100 & 0.71 & 3.0 \\
\hline 3 & $\mathrm{EtOAc} / \mathrm{CH}_{2} \mathrm{Cl}_{2}$ & 50 & 0.33 & 1.4 \\
\hline 4 & $\mathrm{CH}_{2} \mathrm{Cl}_{2}$ & 100 & 0.10 & 0.4 \\
\hline 5 & $\mathrm{CH}_{2} \mathrm{Cl}_{2}$ & 100 & 0.12 & 0.5 \\
\hline 6 & $\mathrm{CH}_{2} \mathrm{Cl}_{2}$ & 100 & 0.02 & 0.09 \\
\hline 7 & $\mathrm{CH}_{2} \mathrm{Cl}_{2} / \mathrm{MeOH}$ & 90 & 2.15 & 9.2 \\
\hline 8 & $\mathrm{CH}_{2} \mathrm{Cl}_{2} / \mathrm{MeOH}$ & 90 & 1.34 & 5.7 \\
\hline 9 & $\mathrm{CH}_{2} \mathrm{Cl}_{2} / \mathrm{MeOH}$ & 90 & 2.07 & 8.8 \\
\hline 10 & $\mathrm{CH}_{2} \mathrm{Cl}_{2} / \mathrm{MeOH}$ & 80 & 1.37 & 5.9 \\
\hline 11 & $\mathrm{CH}_{2} \mathrm{Cl}_{2} / \mathrm{MeOH}$ & 80 & 0.86 & 3.7 \\
\hline 12 & $\mathrm{CH}_{2} \mathrm{Cl}_{2} / \mathrm{MeOH}$ & 70 & 1.49 & 6.4 \\
\hline 13 & $\mathrm{CH}_{2} \mathrm{Cl}_{2} / \mathrm{MeOH}$ & 70 & 1.55 & 6.6 \\
\hline 14 & $\mathrm{CH}_{2} \mathrm{Cl}_{2} / \mathrm{MeOH}$ & 60 & 0.21 & 0.9 \\
\hline
\end{tabular}

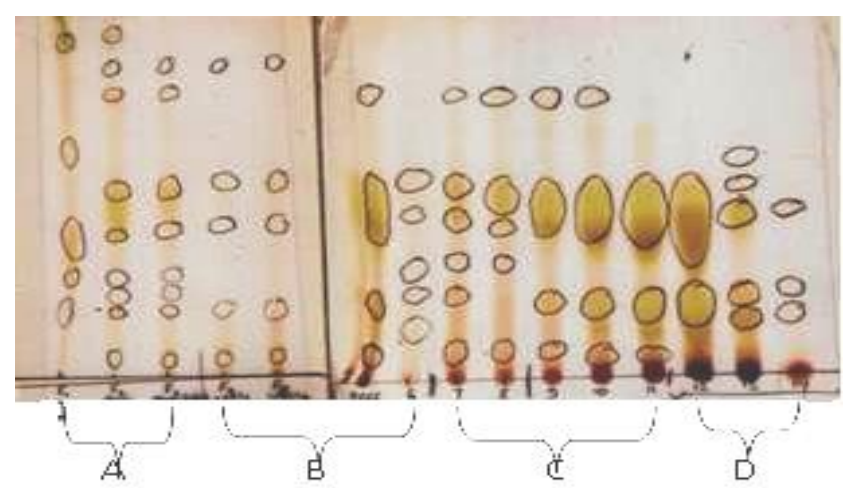

Figure 13. TLC cards VI; Fractions from the 2nd column of Cicer arietinum leaf

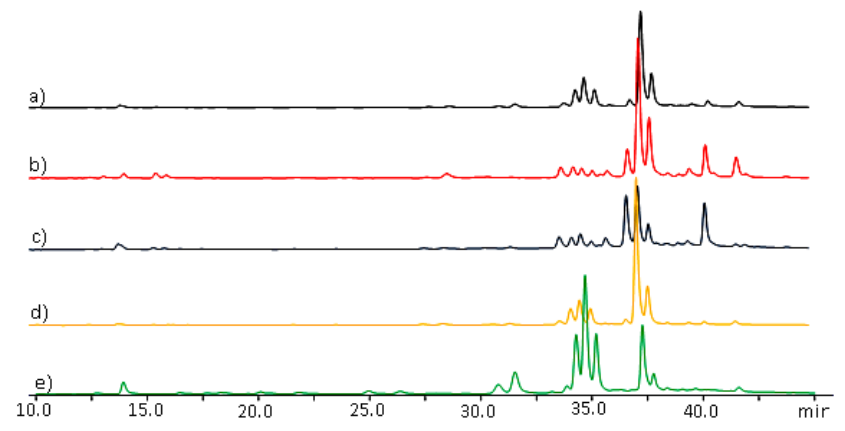

Figure 14. HPLC profiles of fractionations from 2nd column chromatography of Cicer arietinum leaf II. a) Crude sample; b) Fraction A; c) Fraction B; d) Fraction C; e) Fraction D

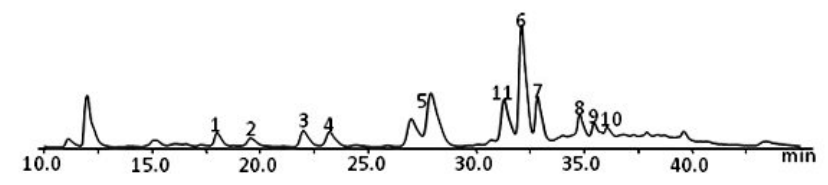

Figure 15. The segregated peaks from Cicer arietinum leaf's fraction D 
Utilizing the LC-MS, TIC traces in positive mode at soft ionization $\left(25^{\circ} \mathrm{eV}\right)$ and strong ionization $\left(40^{\circ} \mathrm{eV}\right)$ conditions were monitored, and relevant pseudomolecular ions $[\mathrm{M}+\mathrm{H}]^{+}$were gained. Weights of purified samples and their respective molecular ions are shown in Table 8.

Analysis utilizing the RP-HPLC showed nine extracts; CAL 1, CAL 2, CAL 3, CAL 4, CAL 7, CAL 8, CAL 9, CAL 10, and CAL 11, which were substantial concentrations and gave characteristics of single peaks at their respective retention times. It meant that they were good enough to be described utilizing the LC-MS. But CAL 5 and CAL 6 each produced twin peaks that were inseparable utilizing HPLC, and therefore, they were not good enough to be described utilizing the LC-MS

Utilizing the LC-MS, seven of the above mixtures, which TIC scans gave single peaks each and had flavonoid aglycone based on the Phenol-Explorer database (Anon 2012), were distinguished in this research. Though pure, CAL 1 and CAL 10 were not distinguished in this research since their aglycone is not of any reported flavonoid.

\section{Vigna radiata roots}

Column chromatography. A $270.7 \mathrm{ml}$ normal phase column was packed, and $2.5 \mathrm{~g}$ of $V$. radiata root distillate was eluted utilizing solvents of varying polarity from hexane to methanol. The results are presented in Table 9.

In gathering the fractions, the samples were spotted on pieces of silica gel TLC cards. Utilizing relevant mobile phases, 20:80, 80:20 Hex: EtOAc and EtOAc- $\mathrm{H}_{2} \mathrm{O}-\mathrm{HCO}_{2} \mathrm{H}$ 18:1:1, the spots were expanded (Figure 16).

Comparing the number of fractions per spot and the pigmentation of the eluted spots per sample (Figure 16) above, the fractions were pooled into seven fractions. Then utilizing the HPLC set at $270 \mathrm{~nm}$, the samples were examined (Figure 17). The peaks in fraction $\mathrm{F}$ were segregated utilizing the HPLC instrument.

Description of isolates. Utilizing a short technique that lasted 30 minutes, eight peaks were each segregated from the roots of $V$. radiata (Table 10 ). Utilizing the LC-MS, TIC traces in positive mode at soft ionization and strong ionization conditions were monitored, and relevant pseudomolecular ions $[\mathrm{M}+\mathrm{H}]^{+}$were gained.
Table 9. Fractionation of Vigna radiata root utilizing column chromatography

\begin{tabular}{|c|c|c|c|c|c|}
\hline $\begin{array}{l}\text { Combi- } \\
\text { ned } \\
\text { fraction }\end{array}$ & Fraction & Solvent system & $\begin{array}{l}\% \\
\text { Conc. }\end{array}$ & $\begin{array}{l}\text { Combined } \\
\text { weight (g) }\end{array}$ & $\begin{array}{l}\% \\
\text { Harvest }\end{array}$ \\
\hline \multirow[t]{3}{*}{$\overline{\mathbf{A}}$} & 1 & Hexane/EtOAc & 50 & 0.16 & 6.4 \\
\hline & 2 & Hexane/EtOAc & 50 & & \\
\hline & 3 & Hexane/EtOAc & 50 & & \\
\hline \multirow[t]{5}{*}{ B } & 4 & Hexane/EtOAc & 50 & 0.06 & 2.4 \\
\hline & 5 & Hexane/EtOAc & 50 & & \\
\hline & 6 & Hexane/EtOAc & 50 & & \\
\hline & 7 & EtOAc & 100 & & \\
\hline & 8 & EtOAc & 100 & & \\
\hline \multirow[t]{6}{*}{ C } & 9 & EtOAc & 100 & 0.24 & 10.0 \\
\hline & 10 & $\mathrm{EtOAc} / \mathrm{CH}_{2} \mathrm{Cl}_{2}$ & 50 & & \\
\hline & 11 & $\mathrm{EtOAc} / \mathrm{CH}_{2} \mathrm{Cl}_{2}$ & 50 & & \\
\hline & 12 & $\mathrm{EtOAc} / \mathrm{CH}_{2} \mathrm{Cl}_{2}$ & 50 & & \\
\hline & 13 & $\mathrm{CH}_{2} \mathrm{Cl}_{2}$ & 100 & & \\
\hline & 14 & $\mathrm{CH}_{2} \mathrm{Cl}_{2}$ & 100 & & \\
\hline \multirow[t]{6}{*}{ D } & 15 & $\mathrm{CH}_{2} \mathrm{Cl}_{2}$ & 100 & 0.0012 & 0.05 \\
\hline & 16 & $\mathrm{CH}_{2} \mathrm{Cl}_{2} / \mathrm{MeOH}$ & 90 & & \\
\hline & 17 & $\mathrm{CH}_{2} \mathrm{Cl}_{2} / \mathrm{MeOH}$ & 90 & & \\
\hline & 18 & $\mathrm{CH}_{2} \mathrm{Cl}_{2} / \mathrm{MeOH}$ & 80 & & \\
\hline & 19 & $\mathrm{CH}_{2} \mathrm{Cl}_{2} / \mathrm{MeOH}$ & 80 & & \\
\hline & 20 & $\mathrm{CH}_{2} \mathrm{Cl}_{2} / \mathrm{MeOH}$ & 80 & & \\
\hline \multirow[t]{12}{*}{$\mathbf{E}$} & 21 & $\mathrm{CH}_{2} \mathrm{Cl}_{2} / \mathrm{MeOH}$ & 80 & 0.33 & 13.2 \\
\hline & 22 & $\mathrm{CH}_{2} \mathrm{Cl}_{2} / \mathrm{MeOH}$ & 80 & & \\
\hline & 23 & $\mathrm{CH}_{2} \mathrm{Cl}_{2} / \mathrm{MeOH}$ & 80 & & \\
\hline & 24 & $\mathrm{CH}_{2} \mathrm{Cl}_{2} / \mathrm{MeOH}$ & 80 & & \\
\hline & 25 & $\mathrm{CH}_{2} \mathrm{Cl}_{2} / \mathrm{MeOH}$ & 80 & & \\
\hline & 26 & $\mathrm{CH}_{2} \mathrm{Cl}_{2} / \mathrm{MeOH}$ & 50 & & \\
\hline & 27 & $\mathrm{CH}_{2} \mathrm{Cl}_{2} / \mathrm{MeOH}$ & 50 & & \\
\hline & 28 & $\mathrm{CH}_{2} \mathrm{Cl}_{2} / \mathrm{MeOH}$ & 50 & & \\
\hline & 29 & $\mathrm{CH}_{2} \mathrm{Cl}_{2} / \mathrm{MeOH}$ & 30 & & \\
\hline & 30 & $\mathrm{CH}_{2} \mathrm{Cl}_{2} / \mathrm{MeOH}$ & 30 & & \\
\hline & 31 & $\mathrm{CH}_{2} \mathrm{Cl}_{2} / \mathrm{MeOH}$ & 30 & & \\
\hline & 32 & $\mathrm{CH}_{2} \mathrm{Cl}_{2} / \mathrm{MeOH}$ & 30 & & \\
\hline \multirow[t]{6}{*}{$\mathbf{F}$} & 33 & $\mathrm{CH}_{2} \mathrm{Cl}_{2} / \mathrm{MeOH}$ & 30 & 1.2 & 48.0 \\
\hline & 34 & $\mathrm{CH}_{2} \mathrm{Cl}_{2} / \mathrm{MeOH}$ & 30 & & \\
\hline & 35 & $\mathrm{MeOH}$ & 100 & & \\
\hline & 36 & $\mathrm{MeOH}$ & 100 & & \\
\hline & 37 & $\mathrm{MeOH}$ & 100 & & \\
\hline & 38 & $\mathrm{MeOH} / \mathrm{H}_{2} \mathrm{O}$ & 50 & & \\
\hline
\end{tabular}

Table 8. HPLC, LC-MS, and Flavonoid test analysis of Cicer arietinum leaf extracts

\begin{tabular}{|c|c|c|c|c|c|c|c|}
\hline Fraction & Weight in (mg) & $\%$ age of extract & RT (min) & $\mathrm{UV} \lambda_{\max }(\mathbf{n m})$ & {$[\mathbf{M}]^{+}$} & Purity & $\mathrm{NH}_{3}$ test \\
\hline$\overline{\text { CAL } 1}$ & 0.54 & 0.0008 & $17.9 \sim 18.3$ & $224,239,265,345$ & 610 & Pure & -ve \\
\hline CAL 2 & 1.80 & 0.0025 & $19.3 \sim 19.7$ & $222,238,255,352$ & 640 & Pure & $+\mathrm{ve}$ \\
\hline CAL 3 & 1.70 & 0.0024 & $21.7 \sim 22.1$ & $225,238,257,353$ & 626 & Pure & $+\mathrm{ve}$ \\
\hline CAL 4 & 4.00 & 0.0056 & $22.9 \sim 23.3$ & $230,265,325,337$ & 610 & Pure & +ve \\
\hline CAL 5 & 4.50 & 0.0063 & $\begin{array}{l}25.6 \sim 26.0 \\
26.0 \sim 26.4\end{array}$ & $\begin{array}{l}236,265,347 \\
244,351\end{array}$ & - & Impure & +ve \\
\hline CAL 6 & 1.83 & 0.0026 & $\begin{array}{l}29.1 \sim 29.5 \\
29.8 \sim 30.2\end{array}$ & $\begin{array}{l}232,254,354 \\
236,265,347\end{array}$ & - & Impure & $+\mathrm{ve}$ \\
\hline CAL 7 & 1.70 & 0.0024 & $32.5 \sim 32.9$ & $238,255,352$ & 609 & Pure & $+\mathrm{ve}$ \\
\hline CAL 8 & 2.40 & 0.0034 & $34.5 \sim 34.9$ & $230,265,337$ & 448 & Pure & $+\mathrm{ve}$ \\
\hline CAL 9 & 0.33 & 0.0005 & $36.5 \sim 36.9$ & $220,244,264,348$ & 448 & Pure & +ve \\
\hline CAL 10 & 0.09 & 0.0001 & $37.7 \sim 38.1$ & $224,239,265,348$ & - & Impure & -ve \\
\hline CAL 11 & 0.25 & 0.0004 & $29.4 \sim 29.8$ & $218,244,348$ & 610 & Pure & -ve \\
\hline
\end{tabular}




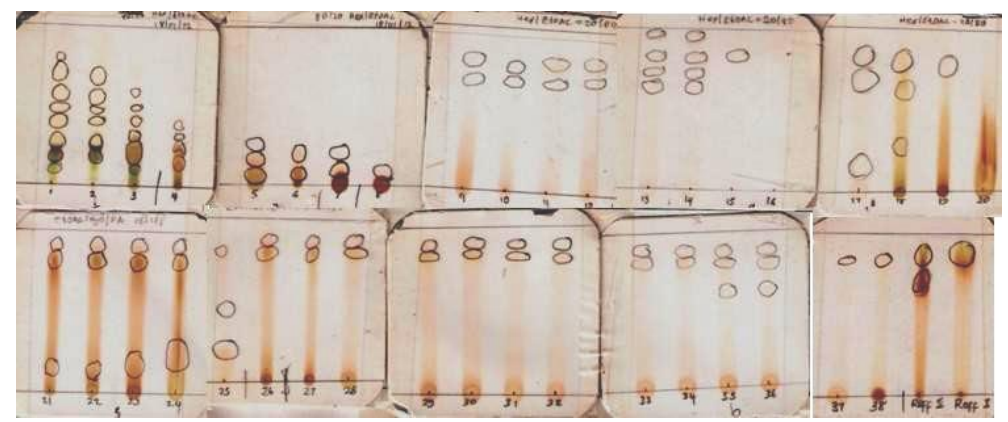

Figure 16. TLC card VII; fractionation of Vigna radiata root by column chromatography

Table 10. HPLC, LC-MS, and flavonoid test analysis of Vigna radiata root extracts

\begin{tabular}{|c|c|c|c|c|c|c|c|}
\hline Fraction & Weight in (mg) & $\%$ of distillate & RT (min) & UV $\lambda \max (\mathbf{n m})$ & Molecular mass $[\mathbf{M}]+$ & Purity & NH3test \\
\hline$\overline{\text { VRR } 1}$ & 1.64 & 0.05 & $5.1 \sim 5.5$ & $227,257,324$ & - & Impure & -ve \\
\hline VRR 2 & 1.50 & 0.05 & $9.8 \sim 10.2$ & $226,244,272$ & - & Impure & -ve \\
\hline VRR 3 & 2.90 & 0.09 & $10.5 \sim 10.9$ & $230,247,295$ & 484,623 & Impure & -ve \\
\hline VRR 4 & 1.70 & 0.05 & $12.8 \sim 13.2$ & 229,257 & - & Impure & -ve \\
\hline VRR 5 & 2.60 & 0.08 & $13.9 \sim 14.3$ & 226,250 & - & Impure & -ve \\
\hline VRR 6 & 1.70 & 0.05 & $16.4 \sim 16.8$ & $219,256,282,319$ & 594 & Pure & -ve \\
\hline VRR 7 & 1.75 & 0.06 & $18.0 \sim 18.4$ & 226,314 & 146,311 & Impure & -ve \\
\hline VRR 8 & 2.41 & 0.08 & $19.7 \sim 21.0$ & $240,299,335$ & $382,461,487,562,592$ & Impure & -ve \\
\hline
\end{tabular}

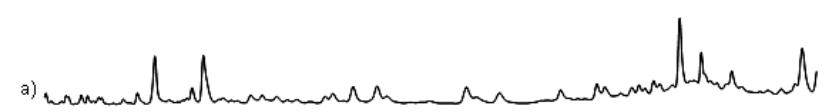

b)

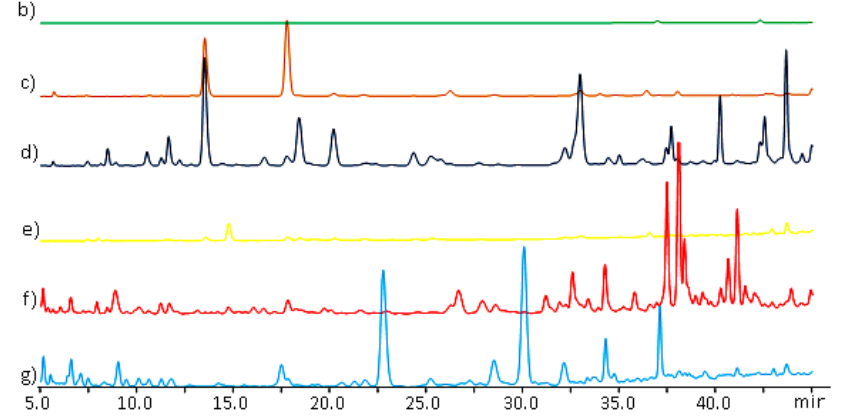

Figure 17. HPLC profiles of Vigna radiata root's fractions a) Crude sample; b) Fraction A; c) Fraction B; d) Fraction C; e) Fraction D; f) Fraction E;g) Fraction F

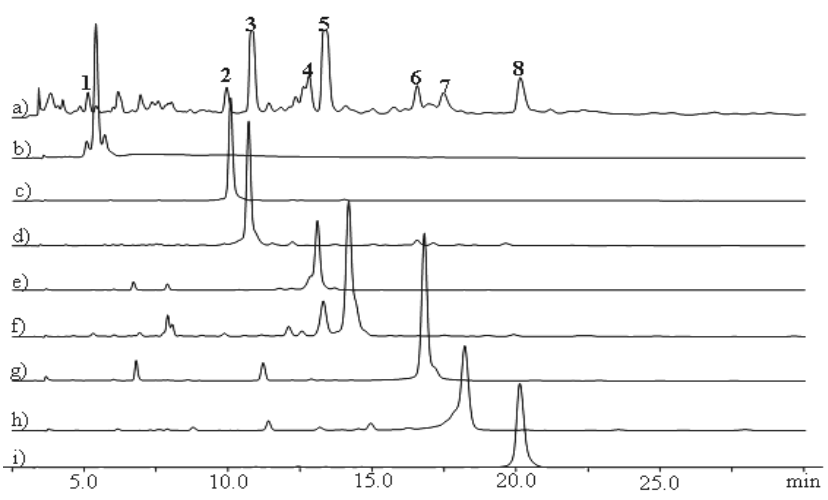

Figure 18. HPLC profile of segregated peaks from Vigna radiata roots' fraction F. a) Fraction F; b) VRR 1; c) VRR 2; d) VRR 3; e) VRR 4; f) VRR 5; g) VRR 6; h) VRR 7; i) VRR 8
Analysis utilizing the RP-HPLC showed all the eight fractions; VRR 1, VRR. 2, VRR 3, VRR 4, VRR 5, VRR 6, VRR 7, and VRR 8, and they were of substantial concentration and gave characteristic of single peaks at their respective retention times (Figure 18). It meant that they were all good enough to be described utilizing the LCMS.

Though all these fractions showed negative results on the ammonium test, VRR 6 had flavonoid aglycon based on the database.

Utilizing the LC-MS, only VRR 6 TIC scans showed a single peak and had flavonoid aglycone based on the Phenol-Explorer database (Anon 2012). It was the only one of the fractions distinguished in this research. The rest of the isolates' TIC scans showed multiple peaks; hence several molecular masses were examined for these fractions.

Though unidentified, VRR 3 showed 3 peaks on the TIC scans, in which one of the peaks had a molecular mass of 484, portraying characteristics of C-Glucosylation characteristics. Fragmentation patterns divulged by the MS technique (Figure 19) supplied structural information about inter glycosidic linkages and aglycone replacement (Andersen 2006). Usually, fragments 162 and 132 amu are gained when the sugar is connected to the aglycone through an O-link. But a direct connection to the aglycone shows characteristic fragmentation of 120 or 90 amu (Andersen 2006). The integrity of the aglycone structure is kept at the expense of the glycan for C-glucosides (Raymond et al. 2006). Two fragmentations were examined on this sample's glycan. 


\section{Identity of the mixtures}

Some of the peak elution times were stable with that of a diglycoside accessible in the icipe's (BCED) library. For this reason, MS scans were arranged up to 1415 mass/charge $(\mathrm{m} / \mathrm{z})$ because most diglycosides possess an $\mathrm{m} / \mathrm{z}$ of 431 to 700 , and a single moiety had 269 to $317 \mathrm{~m} / \mathrm{z}$. Parent peaks were distinguished at 641, 627, 611, 610, 595, 449 , and $431 \mathrm{~m} / z$, with daughter peaks at 317, 312, 303, 287, 271, and $269 \mathrm{~m} / \mathrm{z}$. A subsequent, direct injection MSelectron scan gained these peaks as well as several others in lesser quantities. These masses were compared with all combinations of known diet flavonoid and glycosyl moieties.

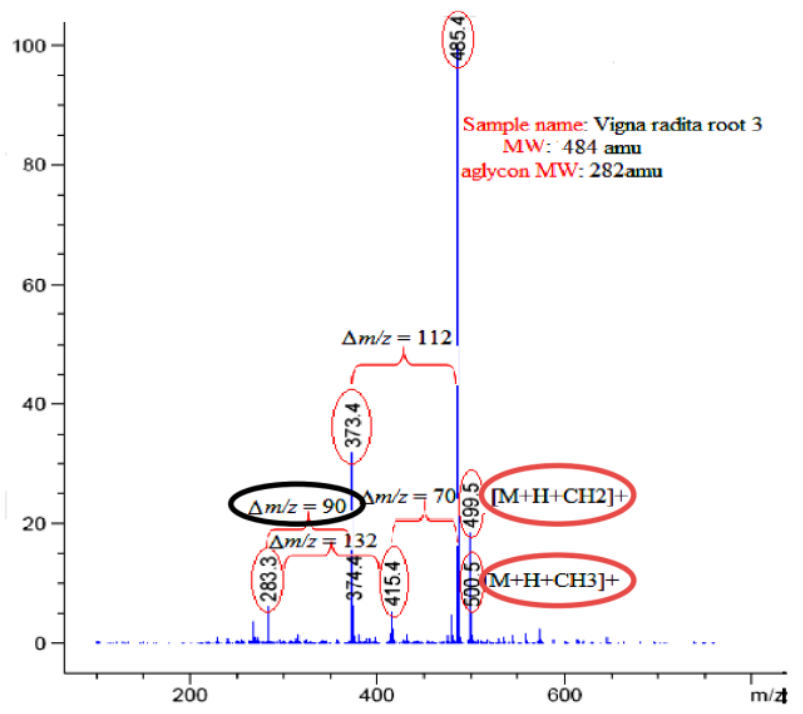

Figure 19. MS fragmentation of C-Glucosylated VRR 3

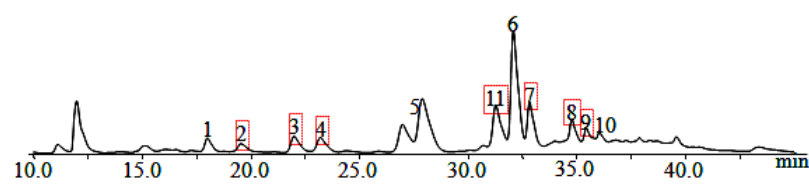

Figure 20.A. Segregated and distinguished mixtures from Cicer arietinum leaf

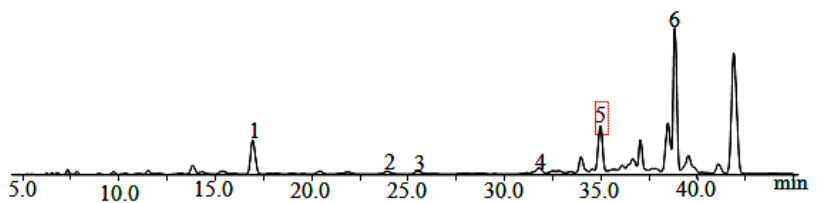

Figure 20.B. The segregated and recognized mixture from Cicer arietinum root

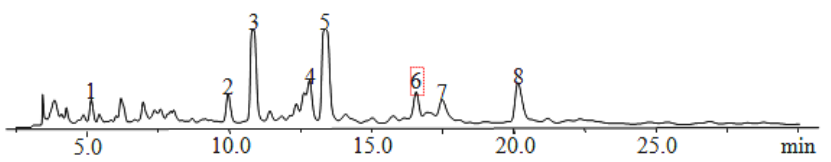

Figure 20.C. The segregated and distinguished mixture from Vigna radiata root
Though eleven fractions were gained from $C$. arietinum leaf (Figure 20.A), only the outlined seven mixtures were distinguished from the plant (CAL 2, CAL 3, CAL 4, CAL 7, CAL 8, CAL 9, and CAL 11) (Figure 20.A). Six fractions were segregated from $C$. arietinum root (Figure 20.B). But only (CAR5) outlined in Figure 20.B was recognized in this study.

In Figure 21.A, a white solid CAR 5 possessed a retention time of 34.1-34.4 min on HPLC. It presented [M $+\mathrm{H}]^{+}$at $m / z 431$ and $[\mathrm{M}+\mathrm{Na}]^{+}$at $m / z 453$, in the positive ion mass spectrum. Therefore, its molecular mass was inferred to be 430 . Its UV spectrum exhibited maximum permeation at $254 \mathrm{~nm}$ and a shoulder peak at $300 \mathrm{~nm}$ with a weak band I $(236 \mathrm{~nm})$ and strong band II $(254 \mathrm{~nm})$. The positive MS spectrum of $\mathrm{m} / \mathrm{z} 431$ indicated ions at $\mathrm{m} / \mathrm{z} 269$ representing a loss of 162 amu recommending the existence of a sugar molecule. In the Phenol-Explorer database (Anon 2012), Formononetin-7- $\mathrm{O}$-glucoside owned a molecular mass of 430 amu. Based on these data, CAR 5 was temporarily recognized as Formononetin-7-Oglucoside.

In Figure 21.B, CAL 2, a yellow solid, possessed a retention time of 19.4 19.7 $\mathrm{min}$ on HPLC. It exhibited $[\mathrm{M}+\mathrm{Na}]^{+}$at $m / z 663$ and an intense $m / z 700$ ions in the normal mass spectra, which disconnected to harvest an $\mathrm{m} / \mathrm{z}$ 641 in the ms 2 spectra. The resulting 59 amu neutral loss indicated the existence of an acetate $\left[\mathrm{M}+\mathrm{H}+\mathrm{CH}_{3} \mathrm{COO}^{\circ}\right]^{+}$ radical ion (confirming $m / z \quad 641$ as the molecular ion). Further disconnection of the $m / z 641$ ions yielded an intense $\mathrm{m} / \mathrm{z}, 479$ in the ms3 spectra, which shows the existence of a terminal galactose sugar (because of the 162 amu neutral loss). An additional $\mathrm{m} / \mathrm{z}, 317$ ion fragment was noticed in the ms 3 ion spectra, showing the existence of another terminal glucose sugar (because of the $162 \mathrm{amu}$ neutral loss). The positive MS spectrum of $m / z 641$ gave fragmentation ions at $\mathrm{m} / \mathrm{z}, 503,479$, and 317 .

Its UV spectrum displayed maximum permeation at 255 and $352 \mathrm{~nm}$, a shoulder peak at $222 \mathrm{~nm}$, and minimum permeation at $245 \mathrm{~nm}$. These data showed that its first aglycon had a molecular mass of 316 . From the precursor ion in the molecule, the existence of two sugar molecules of molecular weights $162 \mathrm{amu}$ is shown. Rhamnetin-3-Ogalactoside-4'-O-glucoside had a molecular mass of 640 amu in the Phenol-Explorer database (Anon 2012). Based on these data, the coalition of the various chromatographic and spectroscopic methods (Table 11), and comparison, CAL 2 was temporarily recognized as rhamnetin-3-Ogalactoside-4'-O-glucoside.

Figure 21.C presented that yellow solid CAL 3 got a retention time of $21.7 \sim 22.1 \mathrm{~min}$ on HPLC. It showed $[\mathrm{M}+\mathrm{H}]^{+}$at $\mathrm{m} / \mathrm{z} 627$ and $[\mathrm{M}+\mathrm{Na}]^{+}$at $\mathrm{m} / \mathrm{z} 650$ in the positive ion mass spectrum, representing that its molecular mass was 626. Its UV spectrum displayed maximum permeation at 238, 258, and $353 \mathrm{~nm}$, a shoulder peak at 225 $\mathrm{nm}$, and minimum permeation at $246 \mathrm{~nm}$.

The positive MS spectrum of $m / z \quad 627$ gave fragmentation ions at $\mathrm{m} / \mathrm{z} 465,446$, and 303. These data showed that CAL 3 was a diglucoside, and the aglycon had a molecular mass of 302. In the Phenol-Explorer database (Anon 2012), quercetin-3,7-O-diglucoside had a molecular 
mass of 626. Based on these data, the coalition of the various chromatographic and spectroscopic methods (Table 11), and comparison, CAL 3 was temporarily recognized as Quercetin-3,7-O-diglucoside.

Figure 21.D indicated that a yellow solid CAL 4 owned a retention time of 22.9 23.2 min on HPLC. It showed [M $+\mathrm{H}]^{+}$at $m / z, 611$ and $[\mathrm{M}+\mathrm{Na}]^{+}$at $m / z 633$ in the positive ion mass spectrum, representing that its molecular mass is 610. Its UV spectrum showed maximum permeation at 265, 325 , and $337 \mathrm{~nm}$, a shoulder peak at $230 \mathrm{~nm}$, and minimum permeation at $245 \mathrm{~nm}$.

The positive MS spectrum of $m / z \quad 611$ gave fragmentation ions at $\mathrm{m} / \mathrm{z} 449,430$, and 287. These data showed that CAL 4 possessed an aglycon of molecular mass of 286. From the precursor ion, the existence of two sugar molecules of molecular weights $162 \mathrm{amu}$ were in the molecule. Sakuranetin-5,4'-O-diglucoside had a molecular mass of 610 on the Phenol-Explorer database (Anon 2012). Based on these data, the coalition of the various chromatographic and spectroscopic methods (Table 11) and comparison CAL 4 was temporarily recognized as Sakuranetin-5,4'-O-diglucoside.

Figure 21.E indicated that a yellow solid CAL 7 had a retention time of 32.6 33.0 min on HPLC. It showed [M $+\mathrm{Na}]^{+}$at $m / z$ 633, $[\mathrm{M}]^{+}$at $m / z 610,[\mathrm{M}+\mathrm{H}]+$ at $m / z 611$ and $[\mathrm{M}+132]^{+}$at $m / z 742$ in the positive ion mass spectrum. Therefore, its molecular mass was ensured to be 610. Its UV spectrum showed maximum permeation at 255 and $352 \mathrm{~nm}$, a shoulder peak at $238 \mathrm{~nm}$, and minimum permeation at $245 \mathrm{~nm}$, recommending that it was an isomer of CAL 2.

The positive MS spectrum of $\mathrm{m} / \mathrm{z} 611$ represented fragment ions at $m / z, 479,461,317$, and 302 ; sequential losses of $132 \mathrm{amu}, 132+\mathrm{H}_{2} \mathrm{O} \mathrm{amu}$, and $162 \mathrm{amu}$ showed the existence of a pentosyl and a glycosyl moiety respectively. The sugar molecules were most likely enclosed in the aglycon, whose molecular mass is $316 \mathrm{amu}$. Based on these and data from the Phenol-Explorer database (Anon 2012), CAL 7 was temporarily recognized as Isorhamnetin-3-Oxyloside-7-O-glucoside.

In Figure 21.F, CAL 8, a yellow solid, had a retention time of $34.6 \sim 35.0 \mathrm{~min}$ on HPLC. It indicated $[\mathrm{M}+\mathrm{Na}]^{+}$at $\mathrm{m} / \mathrm{z} 471$ and $[\mathrm{M}+\mathrm{H}]^{+}$at $\mathrm{m} / \mathrm{z} 449$ in the positive ion mass spectrum. Therefore, its molecular mass was ensured to be 448.

Its UV spectrum showed maximum permeation at 265 and $337 \mathrm{~nm}$, a shoulder peak at $230 \mathrm{~nm}$, and minimum permeation at $246 \mathrm{~nm}$, recommending an isomer of CAL 4. The positive MS spectrum of $m / z 449$ exhibited fragment ion at $m / z$ 287; the loss of $162 \mathrm{amu}$ pointed to a glucosyl enclosed to the aglycon, which molecular mass is 286. Based on these data from the Phenol-Explorer database (Anon 2012), CAL 8 was temporarily recognized as Isosakuranetin-5-O-diglucoside.

In Figure 21.G, CAL 9, a yellow solid, bore a retention time of $36.6 \sim 36.9 \mathrm{~min}$ on HPLC. It exhibited [M $+\mathrm{H}+3 \mathrm{CO}]^{+}$at $m / z$ 533, $[\mathrm{M}+\mathrm{H}+\mathrm{CO}]^{+}$at $\mathrm{m} / z \quad 476$ and $[\mathrm{M}+\mathrm{H}]+$ at $m / z 449$ in the positive ion mass spectrum.

The molecular mass of the mixture was assumed to be 448. Its UV spectrum showed maximum permeation at 244,
264, and $348 \mathrm{~nm}$, a shoulder peak at $220 \mathrm{~nm}$, and minimum permeation at $245 \mathrm{~nm}$, recommending that CAL 9 is neither an isomer of CAL 4 nor of CAL 8.

The positive MS spectrum of $\mathrm{m} / \mathrm{z} 449$ represented fragment ions at $\mathrm{m} / \mathrm{z} 287$. The loss of $162 \mathrm{amu}$ pointed to the existence of a glucosyl fragment and recommended that the glucosyl be enclosed to the aglycon, which molecular mass was 286. In the Phenol-Explorer database on polyphenol content in foods (Anon 2012), luteolin, kaempferol, scutellarein, and fisetin owned a molecular mass of 286. This mixture was neither luteolin nor scutellarein because it was an isomer or the same mixture as CAL 11. Based on these data, CAL 9 was temporarily recognized as; either fisetin-3-O-glucoside, fisetin-7-Oglucoside, fisetin-4'-O-glucoside kaempferol-3-Oglucoside or Kaempferol-7-O-glucoside.

CAL 11 in Figure 21.H, a yellow solid, owned a retention time of 29.4 29.8 $\mathrm{min}$ on HPLC. It exhibited [M $+\mathrm{Na}]^{+}$at $m / z 633$ and $[\mathrm{M}+\mathrm{H}]^{+}$at $m / z 611$ in the positive ionization mode. Therefore, its molecular mass was assumed to be 610 .

Its UV spectrum showed maximum permeation at 244 and $348 \mathrm{~nm}$, a shoulder peak at $218 \mathrm{~nm}$, and minimum permeation at $238 \mathrm{~nm}$ recommending that it was an isomer of CAL 9 but not an isomer of CAL 4. The positive MS spectrum of $\mathrm{m} / \mathrm{z} 449$ indicated fragment ions at $\mathrm{m} / \mathrm{z} 449$ and 287; sequential losses of $162 \mathrm{amu}$, and 2 (162) amu, and showed the existence of two sugar molecules recommending the two glucosyls adhered to the aglycon whose molecular mass is 286. Compared with published data, O-diglucosides of scutellarein is yet to be reported in the diet. Based on these data from the Phenol-Explorer database (Anon 2012), CAL 11 was temporarily recognized as either Fisetin 3,7-O-diglucoside or Kaempferol 3,7-Odiglucoside.

Out of eight fractions segregated from $V$. radiata root (Figure 20.C), only VRR 6 is outlined in Figure 20.C was recognized in this study.

Figure 21.I represented that VRR 6, a red solid, held a retention time of $15.1 \sim 15.4 \mathrm{~min}$ on HPLC. It pointed [M $+\mathrm{Na}]^{+}$at $m / z 617$ and $[\mathrm{M}+\mathrm{H}]^{+}$at $m / z 595$ in the positive ion mass spectrum. Therefore, its molecular mass was assumed to be 594 .

Its UV spectrum represented maximum permeation at 256, 282, and $319 \mathrm{~nm}$, a shoulder peak at $219 \mathrm{~nm}$, and minimum permeation at $245 \mathrm{~nm}$. The positive MS spectrum of $m / z, 432$ represented fragment ions at $m / z 271$, sequential losses of $162 \mathrm{amu}$. It showed that two glucosyls adhered to the Aglycon molecular mass of 270.

Based on these data and the Phenol-Explorer database (Anon 2012), Apigenin, Baicalein, Genistein, and Galangin possess a molecular mass of 270. But a comparison of the UV results of the mixture with Apigenin and Genistein standards indicated that the aglycone of VRR 6 cannot be Apigenin or Genistein. Also, from the database, glucosides of Galangin are yet to be reported. Therefore, VRR 6 was temporarily recognized as Baicalein-7-O-diglucoside. 


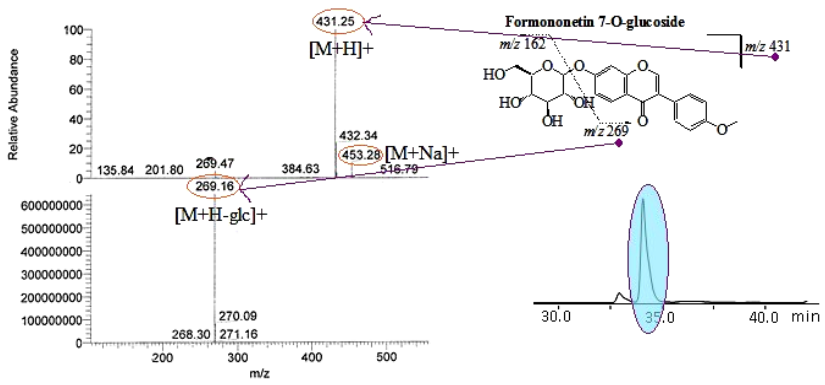

Figure 21.A. HPLC profile, LC-MS fragmentation, and likely structure of CAL 5

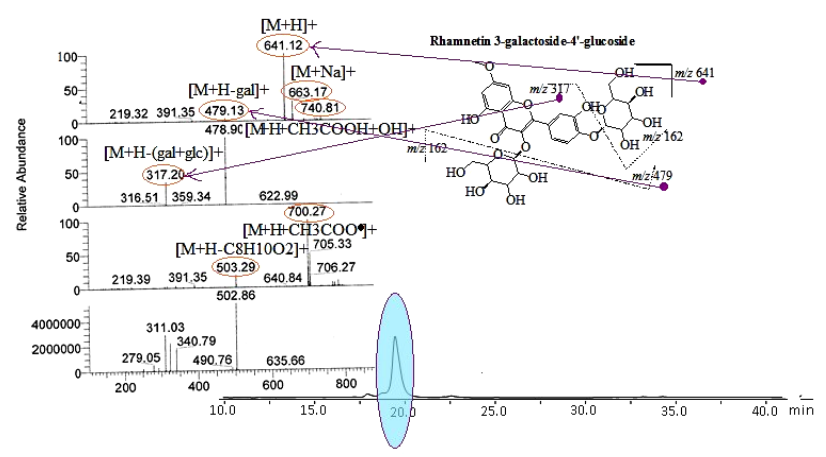

Figure 21.B. HPLC profile, LC-MS fragmentation, and likely structure of CAL 2

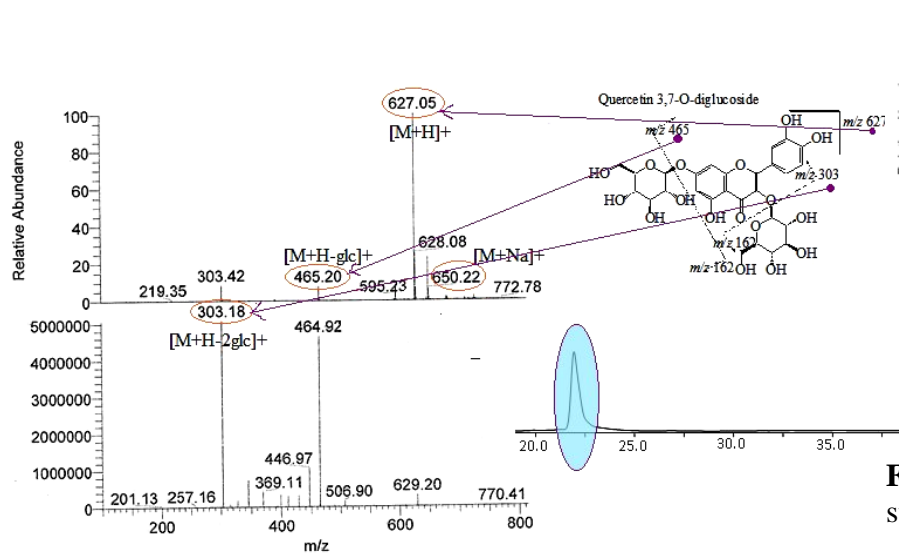

Figure 21.C. HPLC profile, LC-MS fragmentation, and likely structure of CAL 3

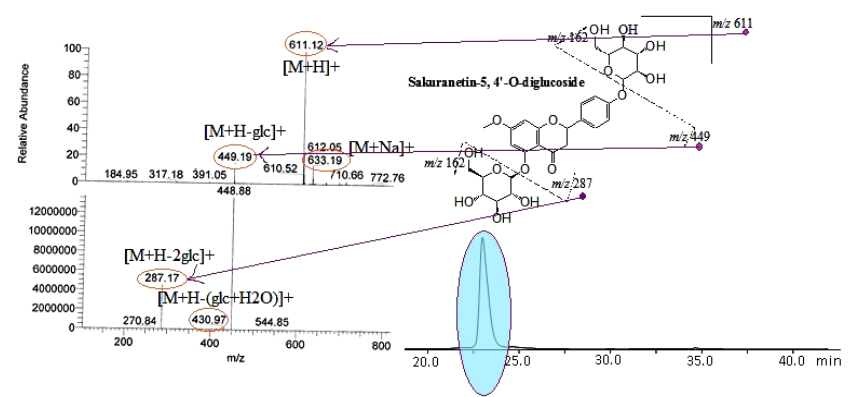

Figure 21.D. HPLC profile, LC-MS fragmentation, and likely structure of CAL 4

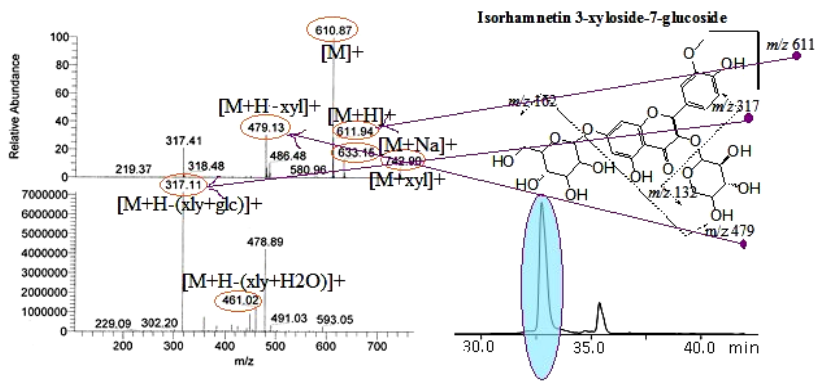

Figure 21.E. HPLC profile, LC-MS fragmentation, and likely structure of CAL 7

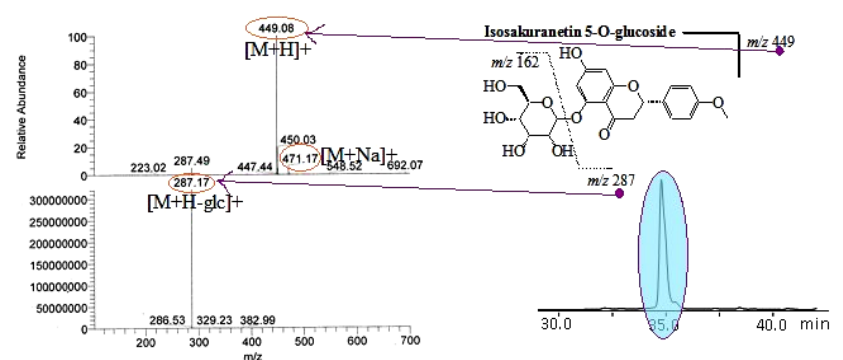

Figure 21.F. HPLC profile, LC-MS fragmentation, and likely structure of CAL 8

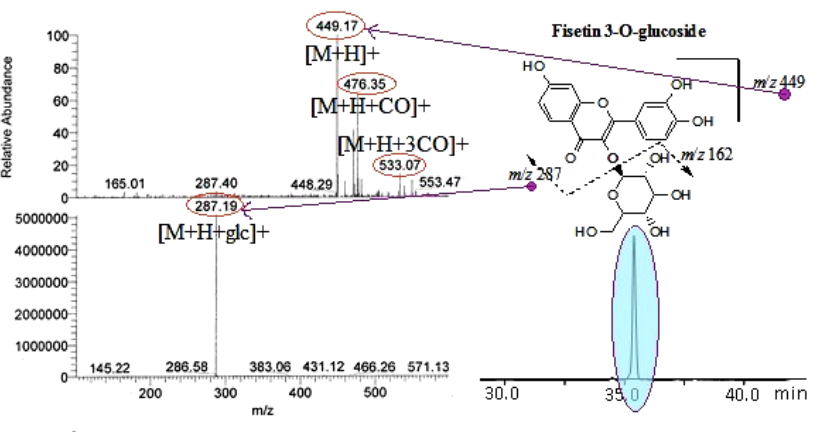

Figure 21.G. HPLC profile, LC-MS fragmentation, and likely structure of CAL 9

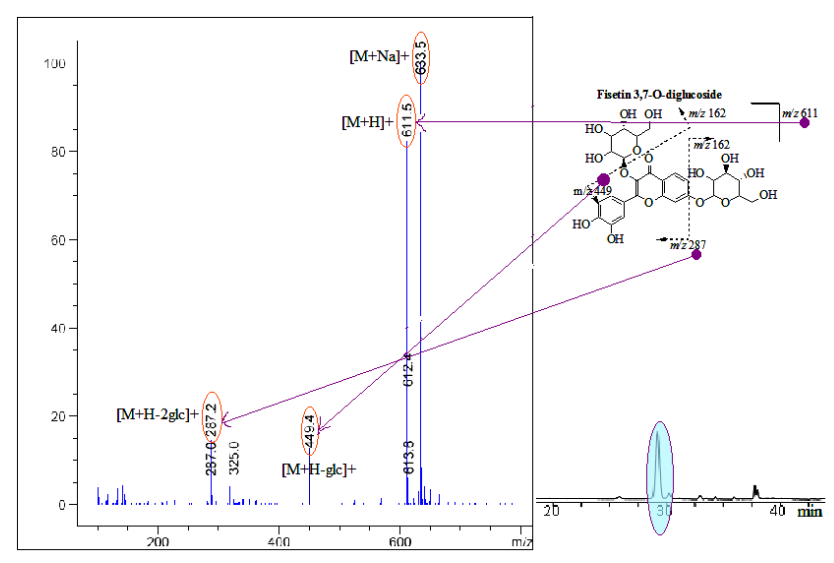

Figure 21.H. HPLC profile, LC-MS fragmentation, and likely structure of CAL 11 


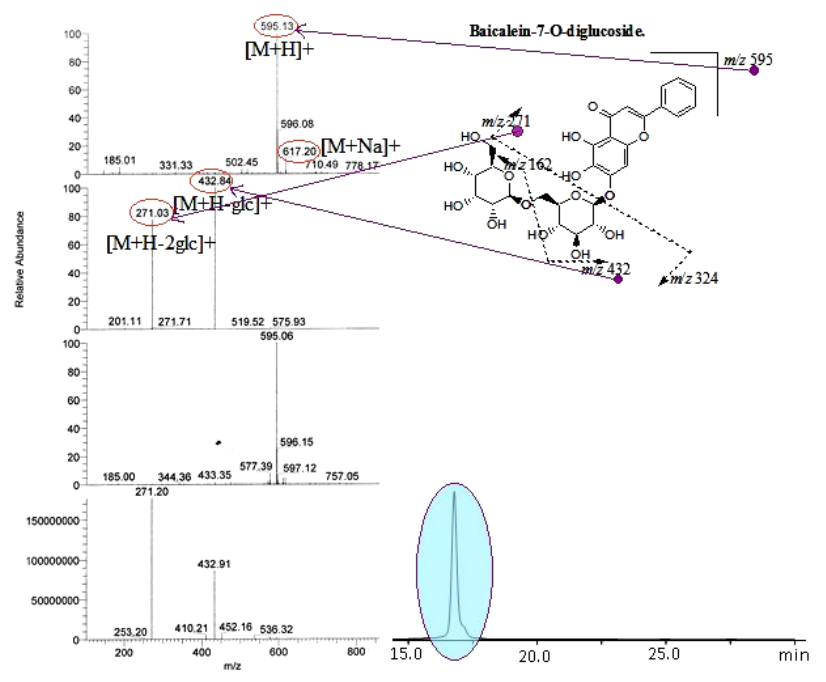

Figure 21.I. HPLC profile, LC-MS fragmentation, and likely structure of VRR 6

\section{Summary of identified mixtures}

Finally, the coalition of the various chromatographic and spectroscopic methods and comparison with published data (Anon 2012) allowed the temporary identification of several mixtures, as summarized in Table 11.

In conclusion, the secondary metabolites segregated from the leaf of $C$. arietinum $\mathrm{L}$. were eleven, and those from the root tissues were six. Description of these metabolites utilizing HPLC and LC-ESI-MS represented that they are all O-glucosylated. It had no inhibitory chemistry and proposed biosynthesis by C-glucosylation (Pickett 2011). The plant gathered several unidentified secondary metabolites in its leaf and root since all the mixtures described and recognized in this research have never been reported before. The ones noticed in the leaf were not replicated in the root or vice versa. Eight secondary metabolites were segregated from the root of $V$. radiata L. Out of these, HPLC and LC-ESI-MS described four mixtures. One mixture, VRR 6, was recognized as Baicelein-7-O-diglucoside. The compound of VRR 3 indicated the characteristic of C-glucoside in MS fragmentation though it was not recognized in this research. This signified that $V$. radiata bore inhibitory chemistry and proposed biosynthesis by $\mathrm{C}$-glucosylation (Pickett 2011).

Table 11. Summary of the temporarily recognized mixtures

\begin{tabular}{|c|c|c|c|c|}
\hline Compound/ possible identification & $\begin{array}{l}\text { Retention } \\
\text { time (min) }\end{array}$ & $\begin{array}{l}\text { UVMaximum } \\
\text { absorbance } \\
(\lambda \max )(\mathrm{nm})\end{array}$ & $\begin{array}{l}\text { ESI-MS fragment ions } \\
(\% \text { proportional intensity) }\end{array}$ & {$[\mathbf{M}]+$} \\
\hline $\begin{array}{l}\text { CAR } 5 \\
\text { Formononetin 7-O-olucoside }\end{array}$ & $34.1 \sim 34.4$ & 236,254 & $\begin{array}{l}\mathrm{m} / \mathrm{z} 453[\mathrm{M}+\mathrm{Na}]+(10) \text { and } 431[\mathrm{M}+\mathrm{H}]+ \\
(100) \mathrm{m} / \mathrm{z} 269[\mathrm{M}+\mathrm{H}-162]+(<5)\end{array}$ & 430 \\
\hline $\begin{array}{l}\text { CAL } 2 \\
\text { Rhamnetin 3-O-galactoside-4'-O- } \\
\text { glucoside }\end{array}$ & 19.4 19. & $222,238,255,352$ & $\begin{array}{l}\text { m/z740[M+CH3COOH+OH]+ }(<5) 663[\mathrm{M}+\mathrm{Na}]+ \\
(30) \text { and641[M+H]+ }(100) \cdot \mathrm{m} / \mathrm{z623}[\mathrm{M}+\mathrm{H}-\mathrm{H} 2 \mathrm{O}]+ \\
(<5), 479[\mathrm{M}+\mathrm{H}-162]+(<5), 317[\mathrm{M}+\mathrm{H}-2(162)]+ \\
(<5)\end{array}$ & 640 \\
\hline $\begin{array}{l}\text { CAL } 3 \\
\text { Quercetin 3,7-O-diglucoside }\end{array}$ & $21.7 \sim 22.1$ & $225,238,258,353$ & $\begin{array}{l}\mathrm{m} / \mathrm{z} 650[\mathrm{M}+\mathrm{Na}]+(<10) \text { and } 627[\mathrm{M}+\mathrm{H}]+(100) \cdot \mathrm{m} / \mathrm{z} \\
465[\mathrm{M}+\mathrm{H}-162]+(5), 446[\mathrm{M}+\mathrm{H}-(162+\mathrm{H} 2 \mathrm{O})]+ \\
(1), 303[\mathrm{M}+\mathrm{H}-2(162)]+(<5)\end{array}$ & 626 \\
\hline $\begin{array}{l}\text { CAL } 4 \\
\text { Sakuranetin-5, 4'-O-diglucoside }\end{array}$ & 23.2 & $230,265,325,337$ & $\begin{array}{l}\mathrm{m} / \mathrm{z} 633[\mathrm{M}+\mathrm{Na}]+(15) \text { and } 611[\mathrm{M}+\mathrm{H}]+ \\
(100) \cdot \mathrm{m} / \mathrm{z} 449[\mathrm{M}+\mathrm{H}-162]+(15), 430[\mathrm{M}+\mathrm{H}- \\
(162+\mathrm{H} 2 \mathrm{O})]+(<2), 287[\mathrm{M}+\mathrm{H}-2(162)]+(5)\end{array}$ & 610 \\
\hline $\begin{array}{l}\text { CAL } 7 \\
\text { Isorhamnetin 3-O-glucoside-7-O- } \\
\text { xyloside }\end{array}$ & $32.6 \sim 33.0$ & $238,255,352$ & $\begin{array}{l}\mathrm{m} / \mathrm{z} 742[\mathrm{M}+132]+(10), 633[\mathrm{M}+\mathrm{Na}]+ \\
(15), 611[\mathrm{M}+\mathrm{H}]+(30) \text { and } 610[\mathrm{M}]+(100) \\
\mathrm{m} / \mathrm{z} 479[\mathrm{M}+\mathrm{H}-132]+(30), 461[\mathrm{M}+\mathrm{H}-(132+\mathrm{H} 2 \mathrm{O})]+ \\
(12), 317[\mathrm{M}+\mathrm{H}-(132+162)]+(20)\end{array}$ & 610 \\
\hline $\begin{array}{l}\text { CAL } 8 \\
\text { Isosakuranetin 5-O-glucoside }\end{array}$ & $34.6 \sim 35.0$ & $230,265,337$ & $\begin{array}{l}\mathrm{m} / \mathrm{z} 471[\mathrm{M}+\mathrm{Na}]+(<10) \text { and } 449[\mathrm{M}+\mathrm{H}]+(100) \\
\mathrm{m} / \mathrm{z} 287[\mathrm{M}+\mathrm{H}-162]+(5)\end{array}$ & 448 \\
\hline $\begin{array}{l}\text { CAL } 9 \\
\text { Fisetin 3-O-glucoside }\end{array}$ & $36.6 \sim 36.9$ & $220,244,264,348$ & $\begin{array}{l}\mathrm{m} / \mathrm{z} 533[\mathrm{M}+\mathrm{H}+3 \mathrm{CO}]+(15), \quad 476[\mathrm{M}+\mathrm{H}+\mathrm{CO}]+(65) \\
\text { and } 449[\mathrm{M}+\mathrm{H}]+(100) . \mathrm{m} / \mathrm{z} 287[\mathrm{M}+\mathrm{H}-162]+(<5)\end{array}$ & 448 \\
\hline $\begin{array}{l}\text { CAL } 11 \\
\text { Fisetin 3,7-O-diglucoside or } \\
\text { kaempherol 3,7-O-diglucoside }\end{array}$ & $29.4 \sim 29.8$ & $218,244,348$ & $\begin{array}{l}\mathrm{m} / \mathrm{z} 633[\mathrm{M}+\mathrm{Na}]+(100) \text { and } 611[\mathrm{M}+\mathrm{H}]+(84) \\
\mathrm{m} / \mathrm{z} 449[\mathrm{M}+\mathrm{H}-162]+(13) \text { and } 287[\mathrm{M}+\mathrm{H}-2(162)]+ \\
(15)\end{array}$ & 610 \\
\hline $\begin{array}{l}\text { VRR } 6 \\
\text { Baicalein-7-O-diglucoside }\end{array}$ & $15.1 \sim 15.4$ & $219,256,282,319$ & $\begin{array}{l}\mathrm{m} / \mathrm{z} 710\left[\mathrm{M}+\mathrm{Na}+\mathrm{C} 6 \mathrm{H} 5 \mathrm{O}^{\cdot}\right]+(<5), 617[\mathrm{M}+\mathrm{Na}]+ \\
(15) \text { and595[M+H]+ }(100) \cdot \mathrm{m} / \mathrm{z} 432[\mathrm{M}+\mathrm{H}-163]+ \\
(<5) \text { and271[M+H-2 }(162)]+(<5)\end{array}$ & 594 \\
\hline
\end{tabular}




\section{REFERENCES}

Ahmed S. 2007. Pharmacognosy, Introduction of plant constituents and their tests. Faculty of Pharmacy, Jamia Hamdard Nagar, New Delhi.

Andersen OM, Markham KR. 2006. Flavonoids, Chemistry, Biochemistry and Applications. CRC Press, USA

Anon. 2012. Phenol-Explorer database on polyphenol content in foods, 16 November 2012 retrieved from: http://www.international.inra.frCompounds' table.

Esilaba AO. 2006. Options for Striga management in Kenya. KARI Technical note, No. 19, March 2006.

Guchu SM. 2007. Studies on Desmodium species for the Allelochemicals involved in Striga suppression. University of Nairobi 87-98 [Unpublished Thesis].

Hooper AM, Hassanali A, Chamberlain K, Khan Z, Pickett JA. 2009. New genetic opportunities for legume intercrops for controlling Striga spp. parasitic weeds. Pest Manag Sci 65 (5): 546-552.

Hooper AM, Tsanuo MK, Chamberlain K, Tittcomb K, Scholes J, Hassanali A, Khan ZR, Pickett JA. 2010. Isoschaftoside, a $C$ glycosylflavonoid from Desmodium uncinatum root exudate, is an allelochemical against the development of Striga. Phytochemistry 71 (8-9): 904-908

Khan ZR, Midega CAO, Bruce TJA, Hooper AM, Pickett JA. 2010 Exploiting phytochemicals for developing a 'push-pull' crop protection strategy for cereal farmers in Africa. J Exp Bot 61 (51): 4185-4196.

Kureh I, Chikoye D, Emechebe AM, Hussaini MA, Kormawa P, Schulz S, Ellis-Jones J, Franke L, Odunze AC. 2003. Reduction of Striga hermonthica parasitism on maize using host plant resistance, n fertilization and rotation with legume trap crop. Afr Crop Sci Soc 6: $167-170$
Othira JO, Deng AL, Onek LA, Kemey J, Omolo EO. 2008. Potential application of Hyptis spicigera for biological control of Striga hermonthica infestation. African J Agric Res 3 (10): 747-755.

Pickett JA, Hamilton ML, Hooper AM, Khan ZR, Midega CAO. 2010. Companion cropping to manage parasitic plants. Ann Rev Phytopathol 48: 161-77.

Pickett JA, Khan ZR, Hassanali A, Hooper AM. 2007. Chemicals involved in post-germination inhibition of Striga by Desmodium: Opportunities for utilizing the associated allelochemical traits. In: Ejeta G, Gressel J (eds.). Integrating New Technologies for Striga control: Towards ending the Witch-Hunt. World Scientific Publishing Company Pte. Ltd., Singapore.

Pickett JA. 2011. Innovations for sustainable intensification of agricultural production: knowledge-intensive routes to doubling yields and reducing inputs. Millennium Address, New Delhi, India

Raymond EM, Errol GL, Christopher JS, Xiu-Sheng M, Xiaoming Z, Chris DM. 2006A comparison of flavonoid glycosides by electrospray tandem mass spectrometry. Intl J Mass Spectrom 248 (12): 61-85.

Rich PJ, Ejeta G. 2008. Towards effective resistance to Striga in Africa maize. Plant Signal Behav 3 (9): 618-621.

Tsai JC, Huang GJ, Chiu TH, Huang SS, Huang SC, Huang TH, LaiSC, Lee CY. 2011. Antioxidant activities of phenolic components from various plants of Desmodium species. Afr J Pharm Pharmacol 5 (4): 468-476.

Tsanuo MK, Hassanali A, Hopper AM, Khan ZR, Kaberia F, Pickett JA, Wadhams LJ. 2003. Isoflavonones from the allelopathic aqueous root exudates of Desmodium uncinatum. Phytochemistry 64: 265-273.

Zaji B, Majd A. 2011. Allelopathic potential of Canola (Brassica napus L.) Residues on weed suppression and yield response of maize (Zea mays L.). International conference on chemical. Ecol Environ Sci 457-460. 